\title{
Photocatalysts with internal electric fields
}

Cite this: Nanoscale, 2014, 6, 24

Received 1st August 2013

Accepted 19th September 2013

DOI: $10.1039 / \mathrm{c} 3 \mathrm{nr} 03998 \mathrm{f}$

www.rsc.org/nanoscale

\author{
Li Li, Paul A. Salvador and Gregory S. Rohrer*
}

The photocatalytic activity of materials for water splitting is limited by the recombination of photogenerated electron-hole pairs as well as the back-reaction of intermediate species. This review concentrates on the use of electric fields within catalyst particles to mitigate the effects of recombination and back-reaction and to increase photochemical reactivity. Internal electric fields in photocatalysts can arise from ferroelectric phenomena, $\mathrm{p}-\mathrm{n}$ junctions, polar surface terminations, and polymorph junctions. The manipulation of internal fields through the creation of charged interfaces in hierarchically structured materials is a promising strategy for the design of improved photocatalysts.

\section{Introduction}

Heterogeneous photochemical reactions on semiconductor surfaces can be used to separate hydrogen from water or to degrade organic pollutants. ${ }^{\mathbf{1 - 4}}$ Hydrogen is an attractive fuel because it has a high energy density and its combustion does not produce greenhouse gases. Furthermore, if sunlight can be used as the source of photons to promote the reaction, then the production and combustion of hydrogen could provide a sustainable energy cycle. Although a practical synthetic strategy has not yet been demonstrated, there have been extensive research efforts directed at finding catalysts for solar hydrogen production. $^{5-14}$ Oxides represent one of the most important classes of photocatalysts and, therefore, there have been a number of recent reviews that have focused on photocatalytic water splitting using metal oxides and on the photochemical properties of oxide surfaces. ${ }^{6,15-21}$ In this review, we discuss some of the challenges associated with optimizing these photocatalysts, and focus on how internal fields can improve photocatalytic properties, as well as strategies to optimize their use in functional catalysts.

Light-driven water splitting processes can be coarsely classified into one of two categories, which are schematically shown in Fig. 1 using the archetypical $\mathrm{Pt}-\mathrm{TiO}_{2}$ materials system. The first is photoelectrolysis, which uses a photoelectrochemical cell, or PEC (see Fig. 1(a)), with Pt and $\mathrm{TiO}_{2}$ as examples of the two separated electrodes. The second is photocatalytic water splitting using colloidal suspensions of powdered catalysts, with $\mathrm{TiO}_{2}$ as the base and Pt as a surface co-catalyst (see Fig. 1(b)). ${ }^{11,22-24}$ The PEC has the advantage that the photogenerated electrons and holes are separated on the macroscale to different electrodes, decreasing recombination and increasing efficiency. Furthermore, hydrogen and oxygen are

Department of Materials Science and Engineering, Carnegie Mellon University, Pittsburgh, PA, USA. E-mail: gr20@andrew.cmu.edu; Fax: +1 412268 7596; Tel: +1 4122682696 evolved in the different locations, diminishing the back reaction of intermediate chemical species and eliminating the need for gas separation. ${ }^{25,26}$ However, the cost of constructing longlived and efficient PECs has been a significant barrier to implementation.

Powdered catalysts, on the other hand, have the potential to be produced at much lower costs through easily scalable processes. Note that the $\mathrm{TiO}_{2}-\mathrm{Pt}$ powdered catalyst can be thought of as a short-circuited version of the PEC; the reactions are spatially separated on the powdered catalyst, but on a much finer length scale than for the PEC. Compared to PECs, powdered catalysts have lower efficiencies. In other words, considering an equal amount of illumination, PECs generally produce more hydrogen. The particles that make up such powdered catalysts have nanoscale dimensions to increase total surface area and the number of available reaction sites. However, the small size of the particles brings several disadvantages. The first is that the interfacial space charge and band bending that tends to separate electrons and holes will not be present when the dimensions of the crystal are comparable to the width of the depletion layer. ${ }^{27}$ The second is that the photogenerated electrons and holes are spatially confined to be in close proximity. These two issues make electron-hole pairs
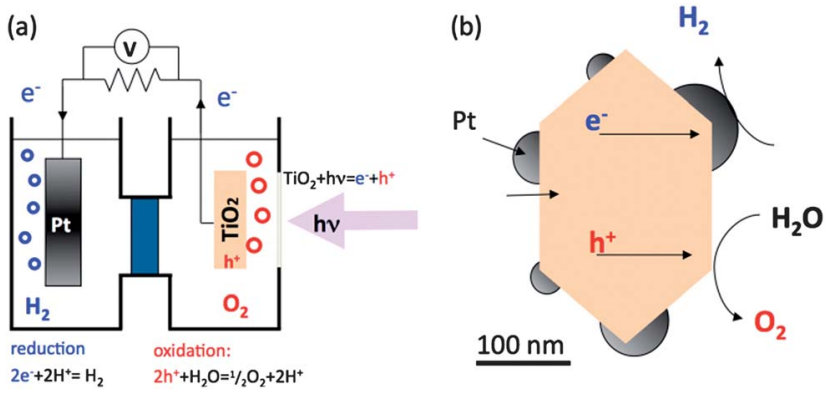

Fig. 1 Simple schematic of (a) photoelectrochemical cell and (b) powdered photocatalyst (adapted from ref. 24). 
more likely to recombine without reacting in small particles than in large particles. The third disadvantage is that the reaction products are also produced in close proximity (on the surface of the small particle) and this makes the back reaction of intermediate chemical species more likely. These three features lead to a loss of efficiency because of the combined effects of the recombination of photogenerated charge carriers and the back reaction of intermediate chemical species. ${ }^{6,18,28-33}$

Good catalysts balance the increase in density of reaction sites for high surface area powders with mechanisms to mitigate the increased recombination and back-reaction rates. Yet, significant room exists for improvement in the technology of photocatalytic water splitting with powdered photocatalysts, and this has motivated considerable research activity over the past decades. At this point, the highest reported quantum efficiency for splitting pure water with visible light and a powdered catalyst is $2.5 \%$ using a $\mathrm{Cr} / \mathrm{Rh}$-modified $\mathrm{GaN} / \mathrm{ZnO}$ material system..$^{7,34,35}$ (The quantum efficiency of a photocatalyst, defined as the ratio of the number of electrons that react to form the product to the number of incident photons, is one useful measure to compare photocatalysts.) In comparison, the maximum theoretical efficiency for water splitting using a semiconductor with a $2.5 \mathrm{eV}$ band gap is $14 \%{ }^{36}$ Clearly, new directions are needed to improve catalyst efficiencies.

One concept that can be used to mitigate losses from recombination and back reaction is to use internal electric fields that will separate photogenerated carriers. Perhaps the best-known examples of these internal fields in photocatalysts are associated with interfaces, including the solution/photocatalyst interfaces, ${ }^{37,38}$ metal cocatalyst-photocatalyst junctions, ${ }^{39,40}$ and $\mathrm{p}-\mathrm{n}$ junctions in composite photocatalysts. ${ }^{\mathbf{4 1 , 4 2}}$ Internal fields at the solution/photocatalyst interface can be modified using different surface terminations, ${ }^{\mathbf{4 3}-46}$ compositions or structures. They can also arise from step functions in the electrochemical levels associated with phase boundaries that are simpler to engineer than $\mathrm{p}-\mathrm{n}$ junctions, ${ }^{47,48}$ including polymorph boundaries in compositionally uniform materials. Finally, they can arise in ferroelectric materials because of internal polar regions. ${ }^{\mathbf{1 6 , 4 9 , 5 0}}$ When they have internal fields, powdered photocatalytic particles behave more like PECs.

This review will focus on recent studies of internal fields and their influence on photochemical reactions on oxide surfaces. We begin by reviewing some of the important materials requirements for photocatalysts and reactions on semiconductor surfaces. We will briefly cover the fundamentals of materials $(\S 2)$ and solution photochemistry ( $§ 3)$ relevant to how internal fields improve photocatalytic performance and discuss how the size of phototcatalysts are coupled with these. We then review recent research exploring the effects of internal fields $(\S 4)$ on photocatalytic water splitting that can arise from: (1) polarity associated with bulk ferroelectricity, and (2) electrochemical differences across phase boundaries, including $\mathrm{p}-\mathrm{n}$ junctions, polar surface terminations on a single phase material, and phase boundaries in compositionally uniform materials. With regard to engineering at the nanoscale, the inclusion of internal fields adds several interesting challenges that point to improved performance through the use of hierarchically structured photocatalysts, or catalysts whose structures include multiple natural length scales. Where appropriate, we will give examples of these materials.

\section{Materials requirements for photocatalysts}

The materials most commonly used for water spitting are semiconductors, although there have been some novel catalysts developed by combining polymers with semiconductors. ${ }^{51-53}$ The overall mechanism for photocatalytic water splitting by a semiconductor (exemplified using $\mathrm{TiO}_{2}-\mathrm{Pt}$ ) is illustrated schematically in Fig. $2 .^{\mathbf{2 4 , 5 4}}$ When the photocatalyst absorbs photons with energies that are greater than the bandgap, electrons are promoted to the conduction band and, if they reach the surface, are available for reduction reactions. Similarly, the remaining holes in the valence band are available for oxidation reactions. In the case of the n-type $\mathrm{TiO}_{2}-\mathrm{Pt}$ example, the electrons are active on the Pt surface and the holes on the $\mathrm{TiO}_{2}$ surface. Even from this simple picture, six intrinsic materials requirements can be articulated for any photocatalyst, originally done so by Morrison. $^{36}$

First, the absorption spectrum of the photocatalyst must have an adequate overlap with the solar spectrum, and this is mostly controlled by the bandgap. The bandgap must obviously be larger than the energy needed to split water $\left(E_{\mathrm{s}}=1.23 \mathrm{eV}\right)$ plus any overpotential for the surface reactions. It is not possible for water splitting to recover all of the energy in the solar spectrum for three main reasons. First, that part of the solar spectrum with energies less than $E_{\mathrm{S}}$ will not split water. Second, when light with an energy greater than $E_{\mathrm{s}}$ is absorbed, the excess energy is not recovered. Finally, in most practical cases the absorption edge of the catalyst is greater than $E_{\mathrm{s}}$ and energy below this edge is also not recovered. Based on these considerations, it has been estimated that the maximum efficiency for water splitting is $14 \%$ for a catalyst with a single bandgap energy of $2.5 \mathrm{eV} .^{36}$

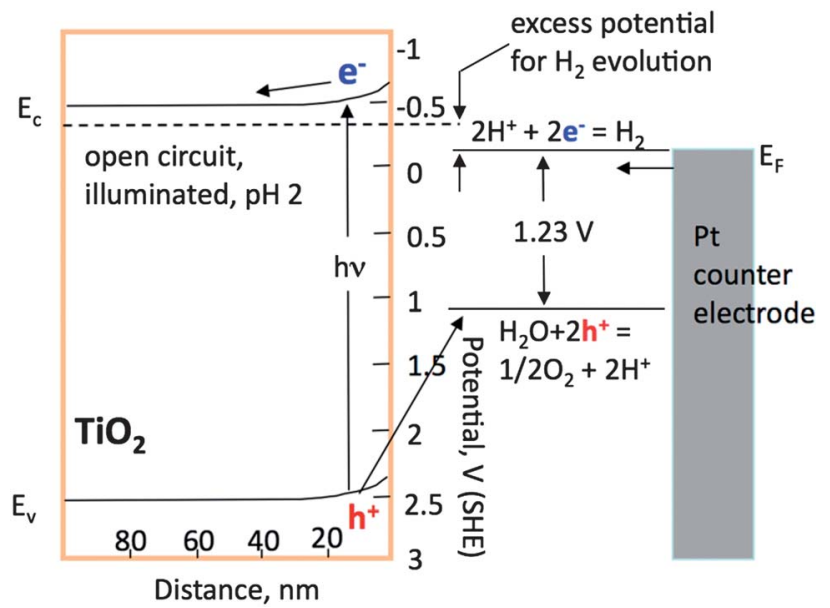

Fig. 2 Schematic representation of water photoelectrolysis using illuminated titania semiconductor electrode (adapted from ref. 24). 
Second, the conduction band edge must be at a higher energy than the reduction potential of hydrogen (plus overpotentials) and the valence band edge must be lower than the oxidation potential of water (plus overpotentials). The band edge positions (relative to the hydrogen scale) of some semiconductors are plotted in Fig. 3 as a function of their bandgap energies. ${ }^{36}$ Note, for any pair of points for a single material, the upper (lower) point indicates the conduction (valence) band edge. The water redox levels are at 0 and $1.23 \mathrm{eV}$ and useful band edge positions are represented as those falling outside the shaded area between these values. Overpotentials are not included in the shaded area because they vary with material and reaction; as such these are the minimal requirements for reaction. Being inside the shaded area rules one out as a candidate. One can safely add the overpotentials to the band gap requirement; assuming that the overpotentials add to roughly $1 \mathrm{eV}$, then a semiconductor's band gap must fall outside of the shaded region from 0 to $2.23 \mathrm{eV}$ to be active for water splitting. Therefore, useful semiconductors for photocatalysts will be those having both band edges outside the shaded region. While there are a limited number of binary compounds that meet these criteria, ${ }^{\mathbf{6}, \mathbf{1 9}, 55}$ suitable compounds may be found among ternary, quaternary, or more complex compounds. So-called $Z$-scheme multi-phase catalysts can be designed from slightly narrower gap materials that have one compound well suited for reduction and the other well suited for oxidation, and such materials have been reviewed elsewhere. ${ }^{6,20,55}$

A third materials requirement is that redox reactions are catalytically activated to reduce the overpotientials. There are generally energy barriers for the transfer of an electron or a hole

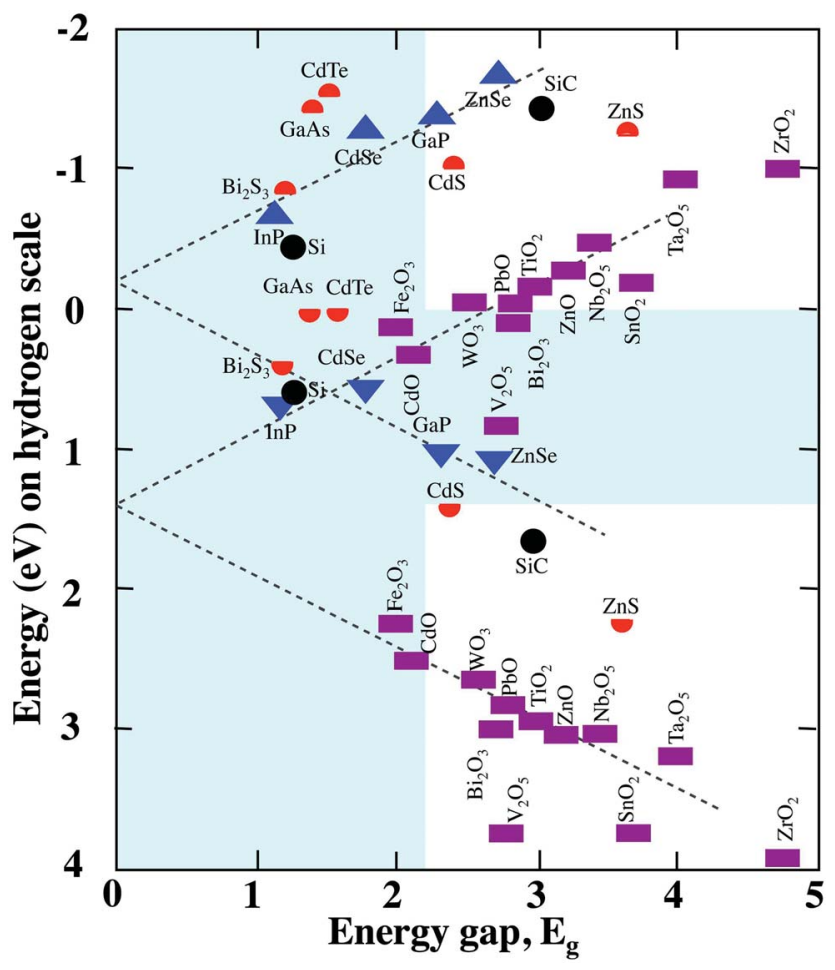

Fig. 3 Schematic representation of the band gap energies and band positions for some semiconductors (adapted from ref. 36). from the surface to species adsorbed from solution. These barriers represent energy that is irreversibly lost in the reaction, so anything that lowers the barrier will promote the reaction. The most common example is the addition of Pt to titania (or other oxides) to promote the reduction reaction. ${ }^{29}$ In other cases, $\mathrm{RuO}_{2}$ is added to promote the oxidation reaction. ${ }^{6}$ The use of co-catalysts to reduce overpotentials is just one example of how composites of multiple phases can be used to produce improved catalysts. Also, co-catalysts are generally much smaller in size than the base catalyst, ${ }^{39}$ because they are more active than the base catalyst and are not (generally) involved in light absorption. This is one clear example of how creating multiple length scales in a single catalytic system leads to improved performance.

A fourth materials requirement is that the catalyst does not dissolve, corrode, or reversibly change during use. There are a number of photocatalysts that have high visible light activity for water splitting but, because of decomposition, lose their photocatalytic activity in a short time. ${ }^{\mathbf{5 6 , 5 7}}$ This may not affect short term laboratory studies, but it is a serious practical concern for the application of photocatalysts. This particular materials requirement is not easily satisfied, as many oxides are slightly water soluble and many ternary oxides can leach alkali and alkaline earth components into water. The remarkable stability of titania is one of the reasons for its common use as a photocatalyst. The lower stability of ferroelectric $\mathrm{BaTiO}_{3}$ in photochemical environments has led to the use of $\mathrm{TiO}_{2}$-coated $\mathrm{BaTiO}_{3}{ }^{58-60}$ Through proper engineering of the heterostructured particles, including hierarchical structures, the composites can be made to perform better than either of the parent phases alone. ${ }^{58-60}$

The fifth and sixth intrinsic materials requirements are that charge carriers be spatially separated to reduce recombination losses and the oxidation and reduction half-cell reactions be spatially separated to reduce the back-reaction of intermediates. Any internal electrochemical field present within the crystal can be used to separate charges, and doing so is the start to satisfying both of these materials requirements. Internal fields may arise from electrochemical potential differences at the junctions of the semiconductor with other solids or solutions, or from the polarization in a ferroelectric material. These mechanisms will be discussed in more detail in $\S 4$.

It should be noted that there are also extrinsic aspects of the catalyst that affect the reaction rates/efficiencies. In this context, the term extrinsic refers to characteristics of the material that are inherited from the processing and can be varied in the synthesis. The principle extrinsic factors are particle size, particle shape, polymorphic form, crystallinity, and non-equilibrium defect structures. For composite catalysts, similar issues related to charge transfer across the interface must also be considered.

Particle size is important because it controls the surface-tovolume ratio. The volume of the catalyst is important for the generation and separation of electron-hole pairs, while the surface is essential for carrying out the heterogeneous reaction. Nanoscale catalysts have the advantage of having large surface areas and, therefore, a larger number of active sites per volume (or mass) of catalyst to promote the reaction. Smaller particle sizes also mean shorter distances for photogenerated charge 
carriers to migrate before reaching surface reaction sites, which can improve performance., ${ }^{\mathbf{6} 61,62}$ However, smaller particle sizes mean that the electron-hole pairs are confined to a smaller space and, therefore, should be more likely to collide and recombine. As a result, electron-hole recombination increases inversely with particle volume. ${ }^{24}$ Clearly the size of an individual particle must be chosen as a compromise between the positive influence of having more reactive sites and the negative influence of increased recombination. Alternatively, one must develop catalyst structures that can exploit the nanoscale improvements while avoiding their detrimental effects. Hierarchically structured catalysts, which combine microscale and nanoscale lengths in powdered catalysts, offer a potential method to simultaneously optimize both requirements. Some examples will be described in $\S 4$.

In addition to the geometric effects, the electronic nature of the catalyst also changes when particles become small enough, and this can also influence reactivity. For example, when the particle size is smaller than twice the width of the surface space charge region present for a bulk material, which is not larger than two times $100 \mathrm{~nm}$ for $\mathrm{TiO}_{2},{ }^{63}$ the bands do not completely relax to the bulk level. Assuming the potential of an electron at the surface is the same, as is shown in Fig. 4, the potential drop and electric field across the space charge region are smaller for small particles. ${ }^{64}$ This should couple directly to the proximity effect, and the recombination rate for photogenerated charge carriers increases with the decrease of particle size in the nanorange. Another electronic effect known for small particles is an increase in the bandgap because of quantum confinement. ${ }^{65-67}$ With regards to photocatalysis, a larger bandgap means less solar energy is harvested, but it may also mean that the band edge positions are modified favorably. Consideration of the electronic features argues that, for most photocatalysts, particles should be large enough to take advantage of band bending, but no larger. In other words, a particle size comparable to twice the width of the space charge region would be appropriate. As before, a balance must be struck between using larger particles for better separation of photogenerated carriers and using smaller particles for maximizing reactive site densities and this can be achieved through hierarchically structured photocatalysts.

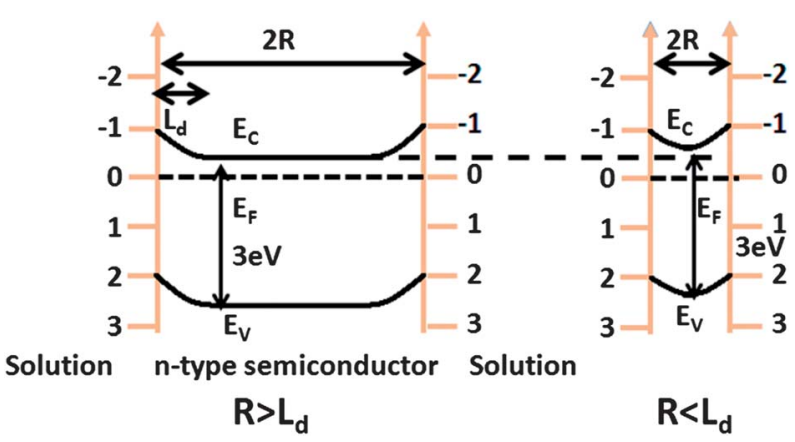

Fig. 4 Band structure of an n-type semiconductor in solution with different particle sizes. (a) $R$ is greater than the space charge width and (b) $R$ is less than the space charge width. $E_{\mathrm{V}}$ is the valence band edge, $E_{\mathrm{F}}$ is the Fermi level, $E_{\mathrm{C}}$ is the conduction band edge, $L_{d}$ is the space charge width (adapted from ref. 64).
The effects of particle shape on photochemistry have also been actively investigated. ${ }^{46}$ It has been demonstrated that some crystal orientations are much more reactive than others and, because of this, one might infer that the overall reactivity could be related to the particle shape. ${ }^{\mathbf{4 6 8 , 6 9}}$ For example, Fig. 5 shows SEM micrographs of faceted $\mathrm{SrTiO}_{3}$ crystals after the photochemical reduction of silver. The silver preferentially reacts on the (100) faces. ${ }^{70}$ Similar phenomena have been observed for rutile, anatase, and $\mathrm{BiVO}_{4} \cdot{ }^{71-73}$ The differences have been correlated to systematic differences in the surface electrochemical potentials, including solid and solution contributions, or anisotropic transport properties along different directions. The former may indicate different internal fields present normal to the different surface orientations. Furthermore, the reactivities of different facets have been correlated to the relative size of faceted particles, indicating the shape and size together play a role in what carrier/reaction is preferred on different surfaces. Because this area has not been thoroughly investigated, it may represent a relatively untapped parameter for designing nanoscale catalysts that overcome some of the inherent limitations imposed by particle size effects discussed above for isotropic particles.

Many oxides can be crystallized in different polymorphs that are metastable in service. $\mathrm{TiO}_{2}$, the most commonly used photocatalyst, has three naturally occurring crystalline polymorphs: anatase, rutile, and brookite; it can also be easily synthesized in structures such as $\mathrm{TiO}_{2}-\mathrm{B}$ or as an amorphous solid. Anatase and rutile are generally regarded to be photocatalytic whereas brookite is not. ${ }^{28,74}$ Anatase is reported to have a higher photocatalytic activity than rutile because of a lower rate of charge carrier recombination and more negative conduction band position. ${ }^{75,76}$ However, rutile displays the same effective photocatalytic decomposition of pollutants. ${ }^{77}$ It has been reported that mixtures of rutile and anatase exhibit enhanced photocatalytic activity compared to the same isolated materials. This has been explained by increased light absorption in rutile and the transfer of photogenerated electrons to trapping sites in anatase, which decreases the recombination of photogenerated charge carriers. ${ }^{78}$ Examples of polymorphic composites are described in more detail in $\S 4.2 .3$.

The degree of crystallinity and the defect content also affect the charge carrier recombination rate, bulk transport, and ultimately the reactivity of the material. In general, almost all typical crystal defects-grain boundaries, dislocations, native point

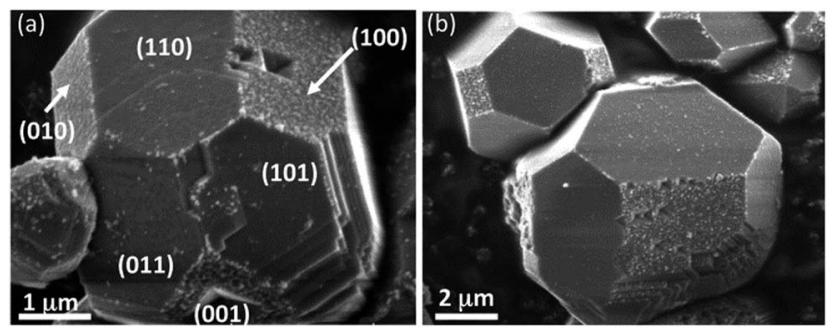

Fig. $5 \mathrm{SEM}$ images of faceted $\mathrm{SrTiO}_{3}$ crystals after exposure to UV light in an aqueous $\mathrm{AgNO}_{3}$ solution. The white contrast on the crystal facets corresponds to silver containing deposits produced by the photochemical reduction reaction. ${ }^{70}$ 
defects, and substitutional impurities-are expected to promote the scattering and recombination of carriers. As such, improved crystallinity, defined as having fewer non-equilibrium defects in the photocatalyst, should lead to improved bulk transport and reduced recombination. ${ }^{6}$ On the other hand, low-temperature and other non-equilibrium preparation routes for the fabrication of metastable or nanophase materials may result in large numbers of defects in otherwise highly reactive systems. Using annealing methods to improve crystallinity can also lead to coarsening or phase transformation, rendering optimal catalyst design in single-phase materials challenging. For example, because the transformation temperature from anatase to rutile in $\mathrm{TiO}_{2}$ is in the range of $500{ }^{\circ} \mathrm{C}$ to $600{ }^{\circ} \mathrm{C}$, at the low-end of the temperature range expected to recover the maximum crystal quality in anatase. Thus, annealing to increase crystallinity of the reactive anatase $\mathrm{TiO}_{2}$ can also lead to transformation to the lower reactivity rutile polymorph. ${ }^{79-81}$ Again, heterostructured catalysts can offer improved design and better processing windows as anatase particles (and other metastable polymorphs) are known to have improved thermal stability on certain types of substrates. ${ }^{\mathbf{9}}$

Many of the above-described extrinsic factors also are relevant to the phase boundary in multi-phase catalysts. Even for the $\mathrm{TiO}_{2}-\mathrm{Pt}$ powdered catalysts, charge transfer at the $\mathrm{TiO}_{2} / \mathrm{Pt}$ interface should be uninhibited, and the interface quality (bonding) will strongly affect this. As with the bulk crystallinity, increased annealing temperatures promote strong interfacial bonding, but come at the expense of coarsening in the cocatalysts (or smaller length scale material). ${ }^{59}$ As such, processing windows must be optimized to increase the interface quality to improve charge transfer while maintaining appropriate particles size/surface coverage, as demonstrated for hierarchically structure catalysts, such as nanostructured $\mathrm{TiO}_{2}$ shells on microcrysalline $\mathrm{BaTiO}_{3}$ cores. ${ }^{59}$

\section{Photochemistry on the semiconductor surface}

\subsection{Energy levels in the semiconductor and solution}

From the discussion of materials requirements in $\S 2$, it becomes obvious that we need a system of evaluating the energies of electrons in solids. Specifically, we need to know the energies levels and their relation to redox couples. Throughout this paper, we shall use the convention that the zero of energy is defined as the hydrogen redox reaction at the normal hydrogen electrode, as defined in Fig. 6. The energy level has been determined to be $4.5 \mathrm{eV}$ lower than an electron at the vacuum level. ${ }^{\mathbf{8 2 - 8 4}}$ By convention, the vacuum level is taken to be negative with respect to the hydrogen ionization reaction.

The semiconductor given in Fig. 6 is shown in the flat band configuration, which simply means that electron potential at the surface and in the bulk are identical (i.e., there is no band banding in the semiconductor). While the bandgaps of materials are often known from optical experiments, the conduction band edge is more difficult to determine experimentally. However, when the band gap $\left(E_{\mathrm{g}}\right)$ is known, there is a simple way to approximate the energy level of the conduction band

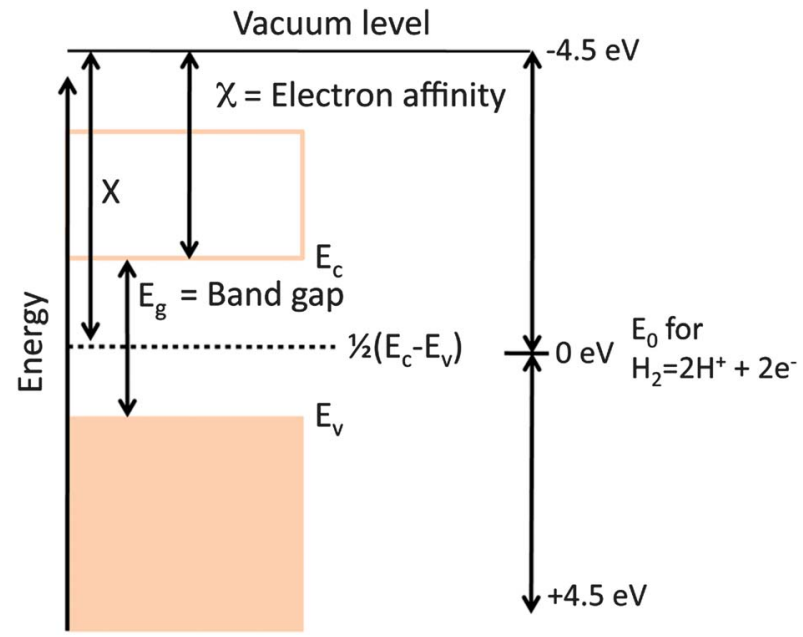

Fig. 6 Schematic representation of some fundamental semiconductor concepts used for photochemical reactions $\left(E_{\mathrm{c}}\right.$ is conduction band, $E_{\mathrm{v}}$ valence band, $X$ is the Sanderson electronegativity of the solid, $E_{0}$ the energy of a free electron at the $\mathrm{H}_{2}$ redox potential).

edge $\left(E_{\mathrm{c}}\right)$ that was originally proposed by Butler and Ginley. ${ }^{85}$ If $X$ is the Sanderson electronegativity of the solid (the energy difference between the vacuum level and the midgap position of the semiconductor), which is defined as the geometric mean of the Mulliken electronegativities the atoms, then $E_{\mathrm{c}}$ is defined as:

$$
-E_{\mathrm{c}}=4.5 \mathrm{eV}-X+1 / 2 E_{\mathrm{g}}
$$

The Mulliken electronegativity of an atom is the average of the first ionization energy of the metal and the atomic electron affinity of the anion. As an example, the ionization energies of $\mathrm{Ti}$ and $\mathrm{O}$ are $6.83 \mathrm{eV}$ and $13.62 \mathrm{eV}$, respectively, and the electron affinities are for Ti and $\mathrm{O}$ are $0.083 \mathrm{eV}$ and $1.46 \mathrm{eV}$, respectively. The Mulliken electronegativies for $\mathrm{Ti}$ and $\mathrm{O}$ are therefore $3.45 \mathrm{eV}$ and $7.54 \mathrm{eV}$, respectively. This leads to a Sanderson electronegativity of $5.8 \mathrm{eV}$ and, assuming a band gap of $3.0 \mathrm{eV}$, the $\mathrm{TiO}_{2}$ flat band potential is $0.2 \mathrm{eV}$ higher (more negative) than the hydrogen redox reaction. ${ }^{36}$ We are reminded of the importance of $E_{\mathrm{c}}$ and $E_{\mathrm{g}}$ in Fig. 2, which together determine whether the band edges are at appropriate levels for photocatalytic water splitting. Internal fields, the focus of this review, determine which type of carriers is preferentially shuttled to the surface.

\subsection{Charge carrier redistribution near the surface for the semiconductor}

Three primary effects cause charge carrier redistribution in the near surface region of the semiconductor. The first effect arises because of the termination of the bonding network at the surface, which causes the electronic states at the semiconductor surface to differ from those of the bulk. This can lead to a redistribution of mobile charge as the surface attracts specific carrier types in different populations than the bulk. Moreover, the nature of these surface states can be perturbed by interactions with the solution. Overall, these states are generally 
difficult to quantify, and are many times overwhelmed for solids in solutions by the other two effects. ${ }^{36}$ Most energy level diagrams of photocatalysts ignore these states. Even though they may be neglected on energy level diagrams, they may lead to states that impact the transfer of electrons across interfaces, affecting overall efficiencies. ${ }^{36}$

The second effect arises from adsorption of ions. When a semiconductor is immersed in aqueous solutions, the surface chemisorbs charged species $\left(\mathrm{H}^{+}\right.$or $\left.\mathrm{OH}^{-}\right)$in different populations, and this can change the $\mathrm{pH}$ of the water. Similarly, the charge adsorbed on the surface can be controlled by adjusting the $\mathrm{pH}$ of the solution. The $\mathrm{pH}$ value at which the concentrations of adsorbed $\mathrm{H}^{+}$and $\mathrm{OH}^{-}$are equal is called the point of zero charge (PZC). The charge on the surface can either be screened within the semiconductor or within the solution itself, depending on which has the higher capacity to screen the charge. For insulators, screening always occurs in the solution Helmholtz and Guoy layers, as there are no available charges to screen the surface in the solid. For metals, charge adsorption is screened easily by mobile charges in the solid. For semiconductors, intermediate behavior may be observed. Assuming non-degenerate semiconductors with gaps wide enough to split water $(\approx 1.5$ to $2.5 \mathrm{eV})$ and concentrated electrolyte solutions typically used for photocatalytic experiments, the charge is screened in the Helmholtz layer. In this scenario, a voltage drop occurs in the Helmholtz layer that varies with $\mathrm{pH}$ away from the PZC. Assuming this to be true, then band diagrams can be drawn for the solid at the PZC for schematic purposes, and the Helmholtz voltage can be added later with no loss in generality. This is often done in papers on photocatalytic powders.

The third effect is related to electron transfer between the semiconductor and the electrolyte solution to achieve equilibrium between the electrochemical potential of electrons in the two materials. To achieve equilibrium, charge will exchange in a preferred direction between the solid and solution until the Fermi level of the semiconductor is equal to the redox potential of the solution, when charge transfer will be equal in both directions. ${ }^{38,86}$ Within the semiconductor, this exchange of charge is accomplished by the redistribution of mobile electrons or holes and the charge equilibration process leaves a region below of the surface that has an imbalance of charge, which is referred to as the space charge region. The local imbalance of charge causes the energy levels (potentials) of electrons (and holes) to spatially vary relative to a fixed reference level, a phenomenon referred to as band bending, because the energy levels of the bands also vary in potential relative to the fixed reference point. As a result, the physical and chemical properties of the space charge region are different from those in the bulk..$^{17,87}$ This potential variation also leads to an internal electric field, which drives excess carriers (such as photogenerated ones) is opposite directions.

Three types of space charge regions can be identified and they are depicted schematically in Fig. 7 for the case of an n-type semiconductor. ${ }^{17,37,88}$ The case in Fig. 7(a) shows the initial (or flat band) condition, which occurs when there is no net charge transfer from the bulk to the surface or solution states. Assuming the Fermi energy of the solid is lower than the redox potential of (a)
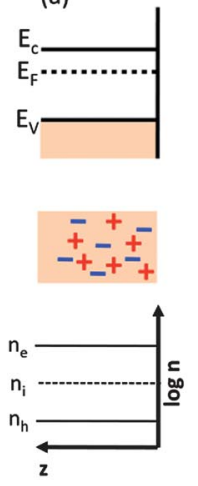

(b)
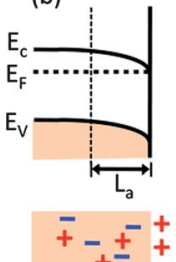

(c)
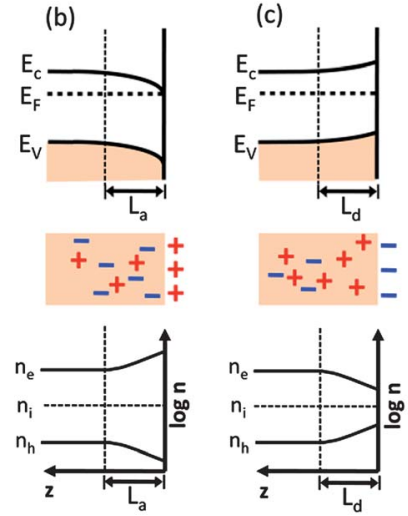
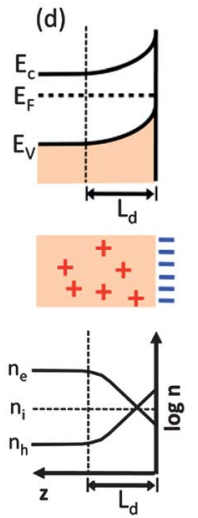

Fig. 7 Schematic diagrams showing the energy levels and free charge carrier densities on (logarithmatic scale) from the n-type semiconductor surface to the bulk. (a) Flat band, (b) accumulation, (c) depletion, (d) inversion. The vertical dashed lines indicate the corresponding space charge region of thickness $L_{d}$ or $L_{a} \cdot n_{e}=$ free electron concentration; $n_{\mathrm{h}}=$ free hole concentration; $n_{\mathrm{i}}=$ intrinsic carrier concentration (adapted from ref. 17).

the concentrated solution, electrons flow from the solution to the solid and lead to the situation depicted in Fig. 7(b). This is known as accumulation, because there is an excess of negative charge in the space charge region below the surface. This excess negative charge exists because the sheet of positive charge in the solution at the semiconductor surface causes a reduction in the energy levels of electrons in this region, compared to the bulk, and downward band bending. The spatial extent of the downward band bending is related to the electronic properties of the semiconductor and the required potential to be dropped across the space charge region, $V_{\mathrm{sc}}$. If the Fermi energy of the solid is at a greater energy than the redox potential of the solution, the opposite will happen, as illustrated in Fig. 7 (c). In this case, charge flows out of the solid, leaving ionized donors and positive charge in the space charge region below the surface, which is known as the depletion layer, and a sheet of negative charge in the solution at the surface of the semiconductor. The negative charge in the solution layer increases the relative potential of the electrons at the semiconductor compared to the bulk, and the bands bend upward as they relax to their equilibrium state. For the case of n-type oxides, these ionized donors are often oxygen vacancies. ${ }^{89,90}$ If there are not enough donors to compensate the charge and it is necessary to extract electrons from the valence band, then an inversion layer forms and the majority charge carrier at the surface changes from electrons to holes, as illustrated in Fig. 7(d).

Note that the existence of other potential drops at the solid/ solution interface will modify the amount of charge transfer required to equilibrate the bulk electrochemical potentials. For example, if the Helmholtz voltage drop associated with ion adsorption is equal in magnitude but opposite in sign to the space charge potential $V_{\mathrm{sc}}$ for any of these cases, the bulk will be at the flat band condition. Also, applied potential differences (dropped across the solid/solution interface, which occur in most conditions described by the prior assumptions) can cause any of the cases of band bending (Fig. 7(a)-(d)) to occur. ${ }^{91}$ 
The subsurface space charge regions where the bands are bent from their equilibrium levels are important for photochemistry because when an electron-hole pair is created in this region, the charge carriers will move in opposite directions, with the electron proceeding to lower energy levels and the hole moving to higher energy levels. Obviously the dimensions of this region are important, especially in comparison to the absorption depth of the light and the size of the particle. The width of the space charge region in depletion $\left(L_{\mathrm{d}}\right)$ or accumulation $\left(L_{\mathrm{a}}\right)$ can be written as a function of the Debye length, $L_{\mathrm{D}}$, and the potential drop across the space charge region, $V_{\mathrm{sc}}$ (which depends on the factors described above). ${ }^{92}$ The Debye length is a characteristic of the material and depends on the dielectric constant and donor concentration according to eqn (1): ${ }^{92}$

$$
L_{\mathrm{D}}=\left(\frac{\varepsilon_{0} \varepsilon_{\mathrm{r}} k T}{e^{2} N_{\mathrm{D}}}\right)^{1 / 2}
$$

where $\varepsilon_{0}$ is the permittivity of free space, $\varepsilon_{\mathrm{r}}$ is the dielectric constant, and $N_{\mathrm{D}}$ is the donor density (assuming an n-type semiconductor). The widths of the space charge layers are then:

$$
L_{\mathrm{d}}=\left(\frac{2 \mathrm{eV}_{\mathrm{s}}}{k T}\right)^{1 / 2} L_{\mathrm{D}}
$$

and

$$
L_{\mathrm{a}}=\sqrt{2}\left(1-\exp \left[\frac{\mathrm{eV} \mathrm{s}}{2 k T}\right]\right) L_{\mathrm{D}}
$$

for depletion and accumulation layers, respectively, and where $e$ is the electron charge, $k$ is Boltzmann's constant in $\mathrm{eV} \mathrm{K}^{-1}$, and $T$ is the absolute temperature.

Using reasonable estimates for these parameters, the width of the depletion region in the materials of interest is in the range of 20 to $100 \mathrm{~nm} \cdot{ }^{17,36,93}$ Recall that when the size of an isotropic particle is less than or equal to twice the width of the space charge region, then the full extent of band bending cannot be sustained. Therefore, spatial separation arising from band bending is expected to be most effective in crystals with diameters greater than approximately $100 \mathrm{~nm}$. The diminished effect of band bending is one of the reasons for enhanced recombination in catalyst particles with sizes less than $100 \mathrm{~nm}$. Moreover, we would like to be able to control band-bending such that different regions of the surface experience different extents of band bending and promote different carriers to move to spatially different locations. This implies we must somehow cause the surface of effective photocatalysts to vary spatially. The most common method is to decorate the surface with a metallic co-catalyst, such as $\mathrm{Pt}$ for $\mathrm{TiO}_{2}$ photocatalysts. Note that simple co-catalyst additions have not yet resulted in technologically useful photocatalysts for water splitting.

\subsection{Light absorption and charge transport}

Important steps in photochemical reactions are the absorption of light and the transport of the photogenerated carriers. Understanding the materials parameters that quantify these processes is important for the design of semiconductor catalysts. The first important parameter is the absorption length of the incident light within the semiconductor. For radiation with energy greater than the absorption edge, the intensity of the incident radiation decreases exponentially with the distance of penetration. The characteristic absorption length is defined as the depth at which the incident intensity is reduced by a factor of $1 / e$. Using Beer's law, ${ }^{\mathbf{9 4}, 95}$ the absorption length, $L_{\mathrm{P}}$, is $1 /$ $\alpha$, where $\alpha$ is the absorption coefficient.

The absorption coefficient is a material's property that depends on the photon energy and increases steeply at the band gap energy. For example, at a photon energy of $3.4 \mathrm{eV}$, the absorption coefficient of rutile is $10^{5} \mathrm{~cm}^{-1} .93,96,97$ This results in an absorption length of about $100 \mathrm{~nm}$. In other words, most electron-hole pairs that are created by light absorption are created in the layer of material within $100 \mathrm{~nm}$ of the surface. It is important to compare this length scale to the width of the space charge region, wherein charge carriers are easily separated by the local field and are less likely to recombine. ${ }^{38,91}$ Those that are created deeper in the materials, where the bands are flat, are more likely to recombine. Recall that in the last section, it was noted that the space charge width within titania is in the range of $100 \mathrm{~nm}$, comparable to the absorption depth.

The charge carrier diffusion length, or the distance that a charge carrier can diffuse before scattering and recombining, is denoted by $L_{\text {diff. }}$ If light is absorbed and carriers are created outside of the space charge region, but within the length $L_{\text {diff }}$, there is chance that they can make it to the space charge region. $L_{\text {diff }}$ is simply the product of the charge carrier diffusion constant and the carrier lifetime. To utilize the most carriers for the reaction, the carrier lifetime and, therefore, the diffusion length, should be maximized. In general, the carrier lifetime increases with the perfection of the crystal.

Based on the above discussion, the ideal photocatalyst is a semiconductor in which the absorption length for the photons in the source of illumination is smaller than the width of space charge region plus the carrier diffusion length. In this case, all photogenerated charge carriers can be separated and have the potential to participate in the reaction. ${ }^{98}$ This also provides some guidance for the selection and design of nanoscale photocatalysts. To maximize light absorption and charge carrier separation, a semiconductor photocatalyst should have a size that is comparable to twice the size of the space charge region. It should be noted, however, that this may also reduce the surface area in a way that compromises any gains in yield. Therefore, improvement in photocatalyst design can be made by incorporating mechanisms to increase charge separation while maintaining high surface areas. Because these length scales are often at odds with one another, catalysts that have more than one length scale are of interest.

\section{Internal fields}

One of the important features limiting the efficiency of photocatalytic water splitting is the recombination of photogenerated charge carriers and the back reaction of intermediate chemical species that recombine to form water. ${ }^{26,99}$ As discussed above, space charges are effective in separating photogenerated carriers. However, in the cases above, the space charge 
characteristics are determined by the surface states and solution. Band bending can also be controlled by polar fields arising from ferroelectric domains, polar surface terminations, or heterojunctions between materials with different Fermi levels. With appropriate control of the built in fields, photogenerated charge carriers can be driven to the different facets of the crystal and thus separate the sites for oxidation and reduction reaction products. ${ }^{38,100-102}$ In this section, the sources of these electric fields and their influence on photochemistry will be discussed.

\subsection{Internal fields in ferroelectrics}

A ferroelectric is an insulating material with two or more discrete stable (or metastable) states of nonzero electric polarization in zero applied electric field; this is referred to as spontaneous polarization. ${ }^{103}$ Ferroelectrics are non-centrosymmetric and the polarization occurs because the positive and negative charges have different centers of symmetry. Any two of the orientation states normally occur along indistinguishable crystallographic directions in the same crystal structure, differing only in the direction of the electric polarization vector. ${ }^{\mathbf{1 0 4}}$ The polarization vector can be switched between these different orientation states with an applied electric field, which couples to the polarization and changes the relative energies of the states. ${ }^{103}$

Spontaneous polarization in ferroelectrics arises from displacements of individual atoms or ions in the crystal structure. ${ }^{105}$ Perovskite oxides, with the general formula $\mathrm{ABO}_{3}$ (where $\mathrm{A}$ and $\mathrm{B}$ represents cationic elements) are among the most extensively studied ferroelectrics. $\mathrm{BaTiO}_{3}$, the first perovskite oxide compound identified as ferroelectric, ${ }^{\mathbf{1 0 3}}$ is used here as an example to introduce polarization effects. Fig. 8(a)-(c) shows the crystal structure of $\mathrm{BaTiO}_{3}$ at different temperatures. ${ }^{106}$ At high temperatures (above $393 \mathrm{~K}$ ), the crystal displays a cubic perovskite structure and there is no spontaneous polarization. When the temperature is below $393 \mathrm{~K}$, but above $278 \mathrm{~K}$, the Ti and Ba are shifted relative to the negatively charged $\mathrm{O}$, which produces the polarization. The shift of atoms along the $\langle 100\rangle$ direction leads to a change of crystal structure from cubic to tetragonal. When the temperature is below $278 \mathrm{~K}$, the preferred displacement direction of atoms changes (from $\langle 100\rangle$ to $\langle 110\rangle$ ) and the structure converts to orthorhombic; below $183 \mathrm{~K}$ it converts to trigonal (with $\langle 111\rangle$ displacements). ${ }^{107}$ The direction of atomic displacement determines the polarization direction. This critical transformation temperature from ferroelectric to nonferroelectric is called the Curie temperature $\left(T_{\mathrm{C}}\right) \cdot{ }^{\mathbf{1 0 6}, 108}$ The high temperature phase that transforms to the ferroelectric below $T_{\mathrm{C}}$ is described as paraelectric. ${ }^{\mathbf{1 0 7}}$

A depolarization field arises in spontaneously polarized domains which acts to neutralize the polarization by the flow of free charge within the crystal or the absorption of ions on the surface of the crystal from the surrounding medium. ${ }^{\mathbf{1 0 7 , 1 0 9}}$ To minimize the depolarization field, the direction of the polarization varies from region to region within the crystal. Any region having a locally uniform polarization is called a domain; the boundary separating two domains is called a domain wall. ${ }^{\mathbf{1 6}}$ The size of a domain is determined from the balance between the energy cost associated with forming the domain wall

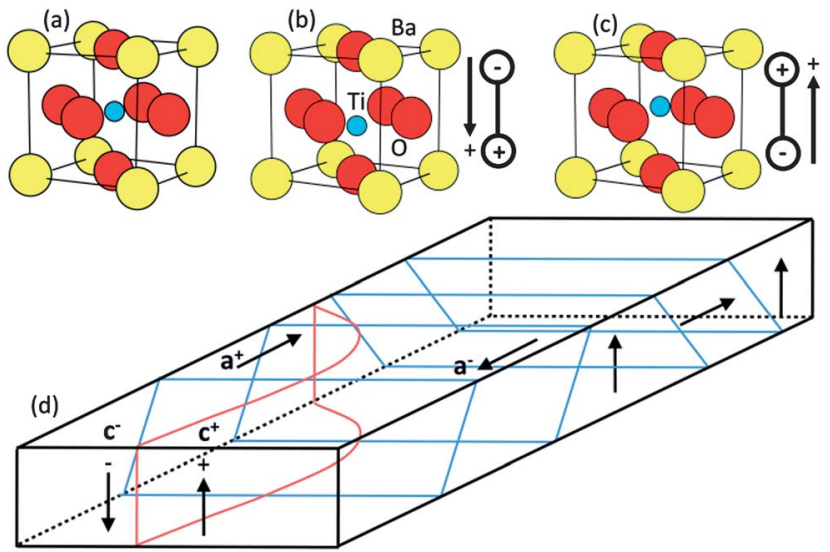

Fig. 8 Atomic structure of $\mathrm{BaTiO}_{3}(\mathrm{a})$ in the cubic form above the Curie temperature; ( $\mathrm{b}$ and $\mathrm{c}$ ) below the Curie temperature, the position of the Ti(Iv) atom in the center of the cell determines its dipole moment. Two of six possible orientations are illustrated; (d) domains are volumes of constant polarization separated by domain boundaries. The arrows show the polarization, the blue lines indicate $90^{\circ}$ domain boundaries and the red lines indicate a $180^{\circ}$ domain boundary.

and the energy gain from reducing the depolarization field..$^{104}$ Domain walls are often described by the angle formed between the polarization vectors on either side of the wall. In tetragonal $\mathrm{BaTiO}_{3}$, where the polarization directions are along the pseudocubic $\langle 100\rangle$ directions, domain walls can be either $90^{\circ}$ or $180^{\circ}$. The $90^{\circ}$ and $180^{\circ}$ domain walls are shown in Fig. $8(\mathrm{~d})$. In this figure, " $\mathrm{c}^{+}$" and " $\mathrm{c}^{-}$" refers to domains with polarization vectors along $(+)$ and (-) vertical $z$ direction (vertical), respectively, while " $\mathrm{a}^{+}$" and " $\mathrm{a}$ " represents domains along the horizontal $a$-axis.

For photocatalyst design, it is necessary to understand the influence of crystal size on the spontaneous polarization. It is known that the measured spontaneous polarization decreases with decreasing particle size in the nanoscale size range. Fig. 9 (ref. 110) show the size effect on spontaneous polarization for one of the common ferroelectrics, $\mathrm{PbTiO}_{3}$. Size dependent ferroelectric polarization is also observed for $\mathrm{BaTiO}_{3} \cdot{ }^{\mathbf{1 1 1}}$ It is

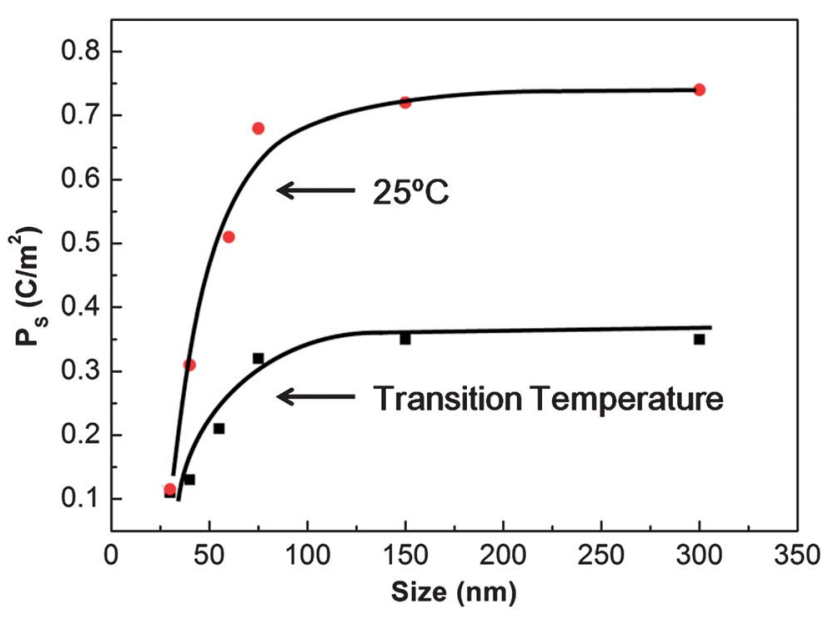

Fig. 9 Variation of spontaneous polarization $\left(P_{\mathrm{s}}\right)$ at transition temperature and at room temperature $\left(25^{\circ} \mathrm{C}\right)$ with particle size for $\mathrm{PbTiO}_{3}$ (reproduced from ref. 110). 
reported that the ratio of the $c$-axis lattice constant to that of the $a$-axis decreases with decreasing particle size. ${ }^{112,113}$ The reduction in tetragonality means that the spontaneous polarization is decreased. ${ }^{\mathbf{1 1 0}}$ As shown in Fig. 9, the ferroelectric polarization decreases for crystal sizes less than $100 \mathrm{~nm}$. The ultimate size limit for the preservation of ferroelectric correlation in the ideal pervoskite is $2.6 \mathrm{~nm} .{ }^{\mathbf{1 1 4 , 1 5}}$ It has recently been reported that $\mathrm{BaTiO}_{3}$ nanocubes, prepared by a two-phase aqueous/organic synthesis procedure, can be switched at room temperature down to sizes as small as $10 \mathrm{~nm}$; it was also shown that ferroelectric switching ultimately disappears in the size range of 5$10 \mathrm{~nm} .{ }^{115}$ It should also be noted that the dielectric constant of ferroelectrics, which influences the width of the space charge region, also decreases significantly with grain size. ${ }^{\mathbf{1 1 6}}$ Although the size dependence of the spontaneous polarization depends on the processing conditions, purity, and stoichiometry, it is best for photocatalytic applications to use particles greater than or equal to $100 \mathrm{~nm}$ so that the maximum intrinsic polarization is available to separate the photogenerated charge carriers.

The internal dipolar field within a ferroelectric creates charged surfaces that cause photogenerated carriers to move in opposite directions, ${ }^{\mathbf{1 1 7}}$ which separates electrons and holes and causes oxidation and reduction products to be generated at different locations. In semiconducting ferroelectrics, the polarization can be screened by internal free charge carriers or defects in the bulk, which causes band bending, as depicted in Fig. 10 (in perfect insulators the potential drops linearly across the domain). ${ }^{118}$ The energy level diagrams are drawn with reference to the standard hydrogen electrode scale, assuming that the band gap of $\mathrm{BaTiO}_{3}$ is $3.2 \mathrm{eV},{ }^{\mathbf{1 1 9}, \mathbf{1 2 0}}$ that the conduction band potential $\left(E_{\mathrm{C}}\right)$ is close to $0 \mathrm{~V},{ }^{121}$ and that the semiconductor is n-type with donor states a few tenths of a volt below the conduction band edge that determine the Fermi level $\left(E_{\mathrm{F}}\right){ }^{\mathbf{1 2 2}}$ For a neutral domain (an a domain, as in Fig. 8), shown in Fig. 10(b), it is assumed that there will be a small amount of upward band bending in a solution with a $\mathrm{pH}$ near 7. For domains in which the positive end of the polarization vector points toward the surface $\left(\mathrm{c}^{+}\right)$, a potential drops across the domain such that the surface is at a lower potential than the bulk. This potential drop reduces the band bending relative to the neutral surface and, depending on

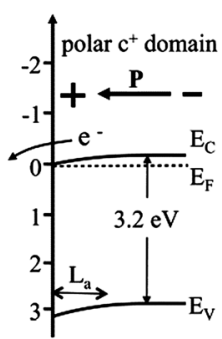

(a)

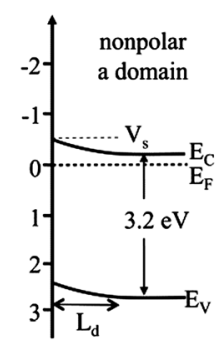

(b)

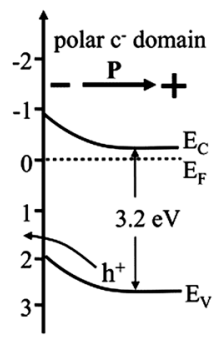

(c)
Fig. 10 Energy level diagrams for $\mathrm{BaTiO}_{3}$ in aqueous solution, without illumination. The energies on the vertical axes are on the standard hydrogen electrode scale. $E_{\mathrm{V}}$ is the valence band edge, $E_{\mathrm{F}}$ is the Fermi level, $E_{C}$ is the conduction band edge, $V_{s}$ is the surface potential, $L_{d}$ is the width of the space charge layer in depletion, and $L_{a}$ is the width of the space charge layer in accumulation. Band bending (a) for a $\mathrm{c}^{+}$ domain, (b) for an a domain, and (c) for a $\mathrm{c}^{-}$domain. the magnitude of $V_{\mathrm{S}}$ on the neutral surface and the ferroelectric potential drop, can even bend the bands downward, as shown in Fig. 10(a) (also it is assumed ferroelectric potential is screened by the accumulation layer of the semiconductor). In this case, the photogenerated electrons can easily reach the surface to react with the solution. ${ }^{123}$ The opposite occurs on negative domains (Fig. 10(c)), where the polarization increases the surface band bending and electrons are further depleted from the surface, with respect to the neutral surface. This obstructs the motion of photogenerated electrons to the surface but promotes the movement of photogenerated holes toward the surface where they can participate in the oxidation reaction. Because these different polarizations occur in spatially distinct domains, the electrons and holes are separated to different surfaces.

Many experiments have confirmed that dipolar fields in the ferroelectrics influence the locations of photochemical reactions. ${ }^{\mathbf{9 9 , 1 0 1 , 1 0 2}}$ These experiments have employed so-called marker reactions that leave insoluble products at the reaction site to determine the correlation between polarization and reactivity. For example, $\mathrm{Ag}^{+}$cations from a silver nitrate solution can be reduced to silver metal and $\mathrm{Pb}^{2+}$ cations from a lead acetate solution can be oxidized to form $\mathrm{PbO}_{2}$. The atomic force microscope (AFM) images in Fig. 11 show the surface of a $\mathrm{BaTiO}_{3}$ ceramic before (11(a and b)) and after (11(c and d)) using the surface to photocatalyze these reactions. ${ }^{63}$ The dark contrast in Fig. 11(b) corresponds to positive domains and the white contrast corresponds to negative domains. The image in Fig. 11(c) shows that silver was reduced on the positive domains and the image in 11(d) shows that lead is oxidized on negative domains, indicating that ferroelectric polarization determines the site of the redox reaction and separates the two half reactions to different domains. This same process can occur in microcrystals, as shown in Fig. $12 .{ }^{49}$ These images show that silver is preferentially reduced on $\{001\}$ facets perpendicular to the direction of ferroelectric polarization.
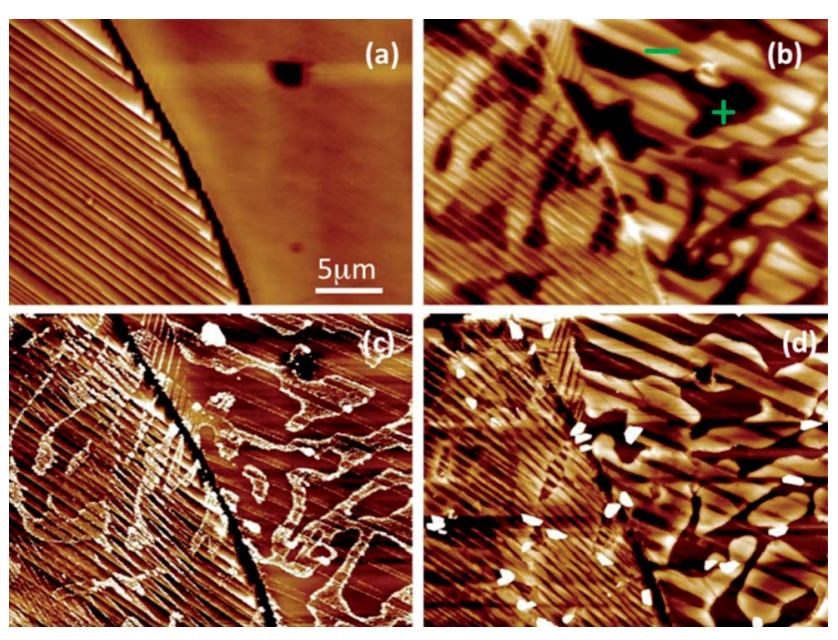

Fig. 11 (a) Topographic AFM images of $\mathrm{BaTiO}_{3}$ surface before reaction and (b), a surface potential image recorded at the same time. (c) Topographic image after reaction in a silver nitrate solution for $3 \mathrm{~s}$. (d) Topographic image after reaction in a lead acetate solution for $3 \mathrm{~min}$. The black-to-white contrast in images a-d are $100 \mathrm{~nm}, 175 \mathrm{mV}, 60$ $\mathrm{nm}$, and $60 \mathrm{~nm}$, respectively (reproduced from ref. 63). 

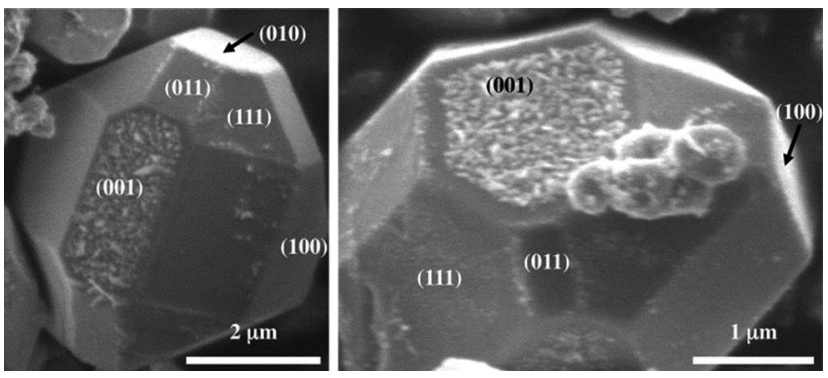

Fig. $12 \mathrm{SEM}$ images of the faceted $\mathrm{BaTiO}_{3}$ crystals after reaction with $\mathrm{AgNO}_{3}$. The speckled white contrast corresponds to silver containing deposits. The patterns of silver indicate that the particles have a single domain (reproduced from ref. 49).

The effects of ferroelectric polarization on photochemical properties are also observed on materials other than $\mathrm{BaTiO}_{3}$. Inoue et al. demonstrated that a positively poled ferroelectric $\mathrm{Pb}(\mathrm{Zr}, \mathrm{Ti}) \mathrm{O}_{3}$ (PZT) produced 10-40 times more hydrogen during photolysis than negatively poled PZT. ${ }^{124}$ Different metal salts have also been photochemically reacted on the surface of PZT, and the location of the product is correlated to the domain structure. ${ }^{\mathbf{1 2 5}}$ Photochemical silver reduction is spatially separated on domains of PZT and different reactivities are observed in different domains. ${ }^{126-131}$ Similar spatially selective reduction of $\mathrm{Ag}$ occurs on the surface of $\mathrm{LiNbO}_{3} \cdot{ }^{132}$ Because of the spatial separation of the redox reactions, $\mathrm{LiNbO}_{3}$ exhibited a high rate of decolorization of organic dyes. ${ }^{\mathbf{1 3 3}}$ Another narrow bandgap ferroelectric, $\mathrm{BiFeO}_{3}$, also preferentially reduces $\mathrm{Ag}$ on domains with the polarization directed towards the surface under visible light irradiation. ${ }^{\mathbf{1 3 4}} \mathrm{BiFeO}_{3}$ nanoparticles synthesized by different methods also show photocatalytic activity for organic dye degradation. ${ }^{\mathbf{1 3 5 - 1 4 0}}$ A number of single-phase ferroelectrics have shown photocatalytic activity either for decomposing organic contamination, carbon monoxide reduction, water splitting, or hydrogen production. ${ }^{\mathbf{1 4 1 - 1 5 0}}$

Ferroelectric polarization also can influence the reactivity of a thin non-ferroelectric coating. Inoue et al. reported that the photocatalytic activity of $\mathrm{TiO}_{2}$ or NiO films supported by poled ferroelectric $\mathrm{LiNbO}_{3}$ was enhanced for one type of domain polarization (positive or negative). ${ }^{151,152}$ If the ferroelectric field from the substrate cannot be screened by carriers at the interface or in the coating, it will influence charge carriers on the surface of the coating. ${ }^{99}$ As shown in Fig. 13, photogenerated charge carriers separated by ferroelectric polarization will participate in redox reactions (silver reduction and lead oxide oxidation) on different domains of the ferroelectric surface and this influence can extended to the surface of a thin coating. ${ }^{153,154}$ AFM images of the (001) oriented $\mathrm{BaTiO}_{3}$ surface and the same orientation coated with $15 \mathrm{~nm}$ of anatase are shown in Fig. 11(c) and $13(\mathrm{~d})$, respectively. It is clear that the patterns of reduced silver on the bare surface and on the coating are similar, confirming the idea that the ferroelectric polarization also can influence the reactivity of the supported coating. ${ }^{153,154}$ In addition to the effect from the substrate, the thickness of the film and the orientation relationship also influence photocatalytic activity. ${ }^{153,154}$ The influence of the substrate is diminished as the
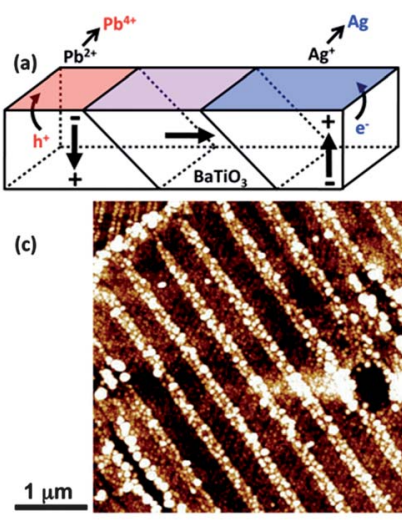

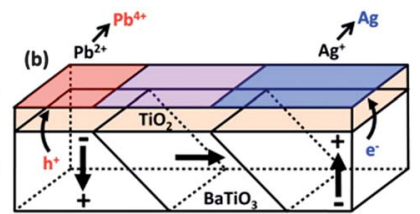

(d)

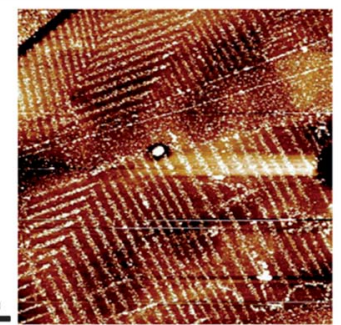

Fig. 13 A schematic illustrating that the ferroelectric domains in the substrate promote the redox reactions on both (a) the bare substrate and (b) films surfaces. The AFM images of (c) (100) oriented $\mathrm{BaTiO}_{3}$ substrate and (d) $15 \mathrm{~nm}$ thick anatase film supported by (100) oriented $\mathrm{BaTiO}_{3}$ substrate after the photochemical reaction in aqueous silver nitrate solution. (The white contrast in (c) and (d) refers to the solid silver after photochemical reduction).

film thickness increases and it eventually disappears for films thicker than $100 \mathrm{~nm}$. Beyond this thickness, the reactivity of the film is similar to bulk titania. ${ }^{154}$ The photochemical reduction of silver by $15 \mathrm{~nm}$ thick $\mathrm{TiO}_{2}$ films supported by $\mathrm{BaTiO}_{3}$ substrates is independent of the phase and orientation, which is contrary to bulk titania. ${ }^{\mathbf{1 5 4}}$ Similar spatially selective photochemical reactions have been observed on $\mathrm{TiO}_{2}$ supported on $\mathrm{BiFeO}_{3} \cdot{ }^{155}$ The patterns of silver reduced from an aqueous silver nitrate solution on a $10 \mathrm{~nm}$ thick $\mathrm{TiO}_{2}$ film mimic the domain structure of the $\mathrm{BiFeO}_{3}$ substrate. This reaction was initiated with visible light, which is not absorbed by the $\mathrm{TiO}_{2}$ coating. This result provides direct evidence that the electrons and holes separated by ferroelectric polarization can transfer from the substrate to the surface of the coating.

The application of heterostructured ferroelectric photocatalysts for water splitting, organic dye degradation, and other uses has also been reported. For example, $\mathrm{PZT} / \mathrm{TiO}_{2}$ nanostructured heterojunctions show enhanced photocatalytic activity for decomposition of ethylene under visible light illumination. ${ }^{\mathbf{1 5 6}}$ Nanostructured composites of $\mathrm{BaTiO}_{3} / \mathrm{TiO}_{2}$ are also reported to show an increased antibacterial photocatalytic activity. ${ }^{60}$ Ag-loaded $\mathrm{BaTiO}_{3} / \mathrm{TiO}_{2}$ nanotubes enhanced charge carrier separation and showed higher photocatalytic reacvitity for methylene blue degradation than their components. ${ }^{157}$ Ferroelectric $\mathrm{PbTiO}_{3}$, when coated with nanostructured $\mathrm{TiO}_{2}$, exhibits improved photocatalytic decomposition of methylene blue under visible light irradiation. ${ }^{50} \mathrm{BiFeO}_{3}-\mathrm{TiO}_{2}$ core-shell nanostructured composites fabricated by the hydrothermal method show a higher photocatalytic activity for the photodegradation of Congo red. ${ }^{158}$ Currently, more and more attention is focused on the application of polarizable semiconductors to control photochemical reactions, and this approach provides a new strategy for heterostructured photocatalyst design. ${ }^{\mathbf{1 6}}$

The use of a ferroelectric internal field within a hierarchically structured photocatalyst provides a reasonable method to 
create more efficient photocatalysts. Micron-sized $\mathrm{BaTiO}_{3}$ cores coated with nanostructured $\mathrm{TiO}_{2}$ showed enhanced photocatalytic activity for hydrogen production compared to the parent phases. ${ }^{\mathbf{5 8}}$ The internal field arising from the micron-sized ferroelectric core, which is also the primary component for light absorption, separates the photogenerated charge carriers. Electrons and holes are transferred through the interface to the nanostructured $\mathrm{TiO}_{2}$ coating, where the charge carriers participate in the redox reaction with water. For this composite, the structural integrity of the interface is important for charge transfer to the coating. At the same time, the high surface area coating provides a large amount of active sites for the reactions. Note that the design of these two phase hierarchically structured materials can improve the stability of the catalyst by protecting a phase susceptible to corrosion with a more stable coating. ${ }^{59}$ By manipulating the processing conditions, hierarchically structured catalysts can also be fabricated to improve their physicochemical properties, such as surface area and porosity. ${ }^{159}$

\subsection{Internal fields at phase boundaries}

4.2.1. $\mathbf{p}-\mathbf{n}$ junctions. The formation of junctions between $n-$ type and p-type semiconductors is the foundation for conventional photovoltaic solar energy conversion. ${ }^{160-168}$ When $\mathrm{p}$-type and n-type semiconductors contact each other, charge is transferred so that the Fermi levels equilibrate. The region in the ntype semiconductor that loses electrons will have a net positive charge. The region in the p-type semiconductor that accepts the electrons will have a net negative charge. At the interface of the semiconductors, bands will bend because of the formation of a space charge region after electron transfer. The charge re-distribution creates an electric field in the space charge region from ntype side to the p-type side. A schematic is shown in Fig. 14. This internal field formed between a p-type and an n-type semiconductor can be used for the separation of photogenerated charge carriers (and to improve the efficiency of photocatalytic water splitting or other photochemical reactions).

The design of heterostructured photocatalysts consisting of $\mathrm{p}$ type and n-type semiconductor components is one of the most common methods to make composite photocatalysts with improved photocatalytic activity. $\mathrm{TiO}_{2}$, the most common photocatalyst studied, is an n-type semiconductor and is self-doped by oxygen vacancies. ${ }^{89,90,169}$ The electronic conductivity of titania is determined by a combination of impurities and the composition of the gas in which it was equilibrated at high temperature. While titania is n-type in nearly all conditions, p-type $\mathrm{TiO}_{2}$ was recently prepared by creating titanium vacancies at elevated temperature and pressure, followed by quenching. ${ }^{170} \mathrm{TiO}_{2}$ has been coupled with different p-type metal oxide photocatalysts, such as $\mathrm{Cu}_{2} \mathrm{O},{ }^{171-175} \mathrm{Ag}_{2} \mathrm{O},{ }^{176-178} \mathrm{Co}_{3} \mathrm{O}_{4},{ }^{179} \mathrm{CuAlO}_{2},{ }^{180} \mathrm{CuBi}_{2} \mathrm{O}_{4},{ }^{181} \mathrm{NiO},{ }^{182,183}$ BiOX (X = Cl, Br, I), ${ }^{184-186} \mathrm{FeTiO}_{3},{ }^{187,188}$ and $\mathrm{ZnMn}_{2} \mathrm{O}_{4},{ }^{172}$ to design efficient heterostructured photocatalysts. Graphene oxide also can be prepared with p-type electrical conductivity. ${ }^{189} \mathrm{TiO}_{2}$ was coupled with graphene oxide to form a $\mathrm{p}-\mathrm{n}$ junction and degraded methylene blue under visible light with wavelengths longer than $510 \mathrm{~nm} .{ }^{190}$ Similar enhancements of the photocatalytic activity of

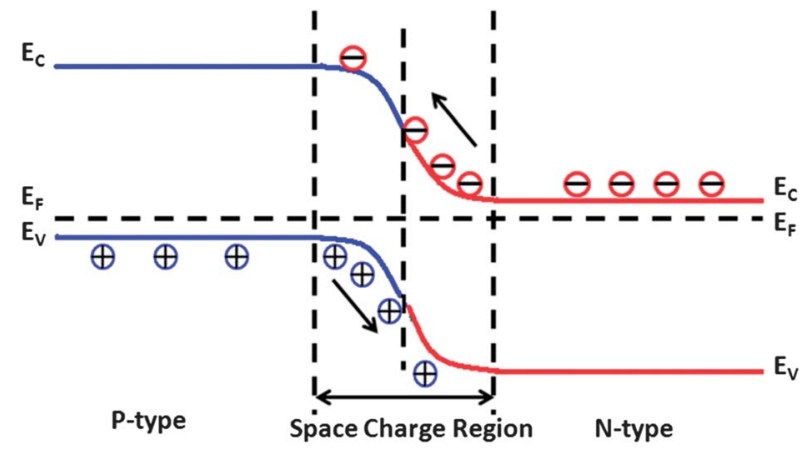

Fig. 14 A schematic illustration of a $p-n$ junction between two semiconductors without an externally applied voltage.

graphene oxide with $\mathrm{TiO}_{2}$ have been reported by others. ${ }^{\text {191-193 }}$ Other photochemically active $\mathrm{p}-\mathrm{n}$ junction combinations, not using $\mathrm{TiO}_{2}$, that have been reported include $\mathrm{NiO} / \mathrm{ZnO},{ }^{194} \mathrm{CaFe}_{2} \mathrm{O}_{4} /$ $\mathrm{Ag}_{3} \mathrm{VO}_{4},{ }^{195} \quad \mathrm{Co}_{3} \mathrm{O}_{4} / \mathrm{BiVO}_{4},{ }^{196,197} \quad \mathrm{CuBi}_{2} \mathrm{O}_{4} / \mathrm{WO}_{3},{ }^{198} \mathrm{BiOI} /$ (BiO) ${ }_{2} \mathrm{CO}_{3},{ }^{199,200} \mathrm{Cu}_{2} \mathrm{O} / \mathrm{In}_{2} \mathrm{O}_{3},{ }^{201} \mathrm{Cu}_{2} \mathrm{O} / \mathrm{BiVO}_{4},{ }^{41} \mathrm{Cu}_{2} \mathrm{O} / \mathrm{WO}_{3}{ }^{202}$ and $\mathrm{Ag}_{3} \mathrm{PO}_{4} / \mathrm{BiPO}_{4} \cdot{ }^{203}$ These nanosized particulate photocatalysts with designs similar to photoelectrochemical and photovoltaic cells show enhanced photocatalytic activity for water splitting and organic dye degradation under UV and visible light. Photocatalytic nanodiodes made up of p-type $\mathrm{CaFe}_{2} \mathrm{O}_{4}$ interfaced with an n-type perovskite $\mathrm{PbBi}_{2} \mathrm{Nb}_{1.9} \mathrm{~W}_{0.1} \mathrm{O}_{9}$ show enhanced photocatalytic activities for oxygen evolution and the degradation of organic pollutants compared to $\mathrm{TiO}_{2-x} \mathrm{~N}_{x}$ under visible light irradiation $(\lambda>420 \mathrm{~nm}) \cdot{ }^{204}$

A $\mathrm{p}-\mathrm{n}$ junction in the same material also can be achieved through the spatial control of doping. For example, it has been reported that p-type $\mathrm{TiO}_{2}$ has been prepared by doping with metal ions, such as $\mathrm{Fe}^{3+},{ }^{205,206} \mathrm{Cr}^{3+},{ }^{207,208} \mathrm{Co}^{3+},{ }^{207,209-212} \mathrm{~V}^{213}$ and N. ${ }^{214}$ It has also been reported that p-type $\mathrm{TiO}_{2}$ also can be prepared by co-doping $\mathrm{C}$ and $\mathrm{W} \cdot{ }^{215}$ The $\mathrm{p}-\mathrm{n}$ contact formed at the junction has been confirmed to assist the separation of photogenerated charge carriers and thus increase the photocatalytic activity of the material. ${ }^{209,216,217}$ It should be noted that though $\mathrm{TiO}_{2}$ can be doped to be a p-type semiconductor, n-type doping is more common. The ability to achieve n-type or p-type doping depends on the positions of the conduction and valance bands. ${ }^{215,218}$ Lower conduction band energies make it easier to dope a material n-type and higher valence band energies make it easier to dope a material p-type. ${ }^{215}$ For example, ZnO, ZnS, CdS and CdTe are easily doped n-type, while ZnTe is more easily doped p-type. ${ }^{215,219-223}$ The $\mathrm{p}-\mathrm{n}$ junction design has also been applied to the design of photoelectrochemical cells for the enhancement of water splitting. A $20 \mathrm{~nm}$ film of p-type hematite doped by $\mathrm{Mg}$ was coated with n-type hematite by atomic layer deposition (ALD) and the homojunction showed a $200 \mathrm{mV}$ turnon voltage shift in the cathodic direction. ${ }^{24}$ The rapid open circuit voltage decay for the $\mathrm{Fe}_{2} \mathrm{O}_{3} \mathrm{p}-\mathrm{n}$ junction indicates the built-in internal fields help to separate charge in the water splitting conditions. The media is also important for adjusting the electrical conductivity of semiconductors. The dominant charge carrier type can be affected by the $\mathrm{pH}$ of the electrolyte and can be tunable from n-type to p-type when prepared in acid 
(a)

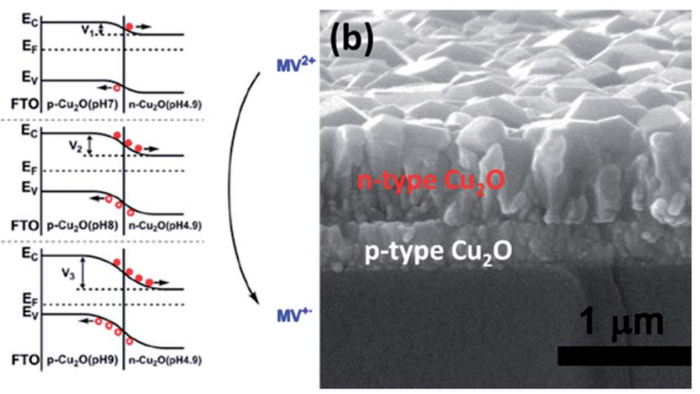

Fig. 15 Energy level diagram and charge transfer process for $\mathrm{Cu}_{2} \mathrm{O} \mathrm{p}-$ $\mathrm{n}$ homojunction prepared by electrodeposition with different $\mathrm{pH}$ conditions for methyl viologen $\left(\mathrm{MV}^{2+}\right)$ photo-reduction to the reduced form $\left(\mathrm{MV}^{+}\right)$, and thus with different magnitude of interfacial electric field. (b) SEM cross section image of $\mathrm{Cu}_{2} \mathrm{O} \mathrm{p}-\mathrm{n}$ homojunction film (reproduced from ref. 228).

or alkaline solutions. ${ }^{225-227}$ As shown in Fig. 15, a $\mathrm{Cu}_{2} \mathrm{O}$ p-n junction film was prepared by a two-step electrodeposition in acid and subsequent alkaline or neutral solution. The final result shows that the $\mathrm{p}-\mathrm{Cu}_{2} \mathrm{O}(\mathrm{pH}=9) / \mathrm{n}-\mathrm{Cu}_{2} \mathrm{O}(\mathrm{pH}=4.9)$ has the largest interfacial electric field and high charge separation efficiency. ${ }^{228}$

Note that a stable interface with a small structural discontinuity between the components at the junctions is important for photogenerated charge carrier transfer. Charge transfer between semiconductor interfaces is finished within picoseconds, ${ }^{\mathbf{4 0 , 2 2 9}}$ and this fast transfer rate requires the interface to provide the smallest penetration barrier. The fabrication of a high quality interfaces in heterostructured catalysts is attracting more and more attention. ${ }^{229-231}$ Previous results showed that micron scale $\mathrm{ATiO}_{3}(\mathrm{~A}=\mathrm{Pb}, \mathrm{Fe})$ coated with nanostructured $\mathrm{TiO}_{2}$ had a higher reactivity for photodecomposition of methylene blue than $\mathrm{AFeO}_{3}$ $(\mathrm{A}=\mathrm{Bi}, \mathrm{La}, \mathrm{Y}) / \mathrm{TiO}_{2}$ processed at the same conditions. ${ }^{232}$ The photocatalytic activity enhancement of titanate $/ \mathrm{TiO}_{2}$ material over ferrite/ $/ \mathrm{TiO}_{2}$ material is attributed to the continuity of bonding at the interface between the titanate core and shell.

Hierarchically structured photocatalysts with $\mathrm{p}-\mathrm{n}$ junctions have also been designed and used for photochemical reactions. $\mathrm{TiO}_{2}$ nanoparticles were deposited on the surface of hierarchical flowerlike NiO and the composites show enhanced photodegradation for p-chlorophenol compared to the components prepared using the same conditions. ${ }^{233}$ The enhanced photocatalytic activity is attributed to the $\mathrm{p}-\mathrm{n}$ junction formation, which provides an internal field for charge separation, and the hierarchical structure, which decreases the aggregation of $\mathrm{TiO}_{2}$ and promotes the transport of reactants and products. Double shell $\mathrm{Bi}_{2} \mathrm{O}_{3} / \mathrm{Bi}_{2} \mathrm{WO}_{6}$ hollow spheres show higher photocatalytic activity than the component phases. ${ }^{234}$ In addition to the formation of a $\mathrm{p}-\mathrm{n}$ junction, the increase of light harvesting in the hierarchical structure leads to an increase of the photocatalytic reactivity. Other hierarchical structures with nanobelt, ${ }^{235}$ nanorod, ${ }^{236}$ and nanobrush $^{237}$ morphologies are widely reported to form $\mathrm{p}-\mathrm{n}$ junctions and promote increased the photocatalytic reactivity.

4.2.2. Polar surface terminations. The structure and composition of the surface influences its physical and chemical properties. One aspect of the surface structure is the polarity. The surface can be polar or non-polar depending on the final plane of atoms. For example, the (100) plane of rock salt $(\mathrm{NaCl})$ is electrically neutral and, therefore, non-polar, because it consists of equal amounts of $\mathrm{Na}$ cations and $\mathrm{Cl}$ anions. On the other hand, the (111) plane consists of either a uniform layer of $\mathrm{Na}$ cations and $\mathrm{Cl}$ anions and is, therefore, polar. ${ }^{238}$ In practice, the so-called 'polar catastrophe' that would occur if a crystal were terminated on a single, atomically abrupt plane, is easily avoided by reconstruction or heterogeneous termination.

Polar surface terminations, even if they only occur locally, can create fields that will influence the photochemical activity of materials. For example, the photochemical reduction of $\mathrm{Ag}^{+}$and oxidation of $\mathrm{Pb}^{2+}$ on the surface of $\mathrm{SrTiO}_{3}$ is anisotropic. ${ }^{43}$ The internal field created by a polar surface termination can promote the separation of photogenerated charge carriers and spatially selective oxidation and reduction. The two AFM images in Fig. 16(a) and (b) are the topography of a (111)-oriented $\mathrm{SrTiO}_{3}$ single crystal before and after photochemical reduction of Ag. The result shows that silver is only reduced on specific terraces, which means the photochemical reduction is spatially separated. This was shown to be correlated to the terminations of the different terraces. The ideal bulk-truncated (111) surface of $\mathrm{SrTiO}_{3}$ can only be terminated by a negatively charged $\mathrm{SrO}_{3}{ }^{4-}$ layer or by a positively charged $\mathrm{Ti}^{4+}$ layer, as shown in Fig. 16(c) and (d). These charged surfaces promote spatially selective oxidation and reduction reactions, similar to those that occur on the different domains of a ferroelectric. The same experiment was performed on (100) surfaces, which can only be terminated by non-polar $\mathrm{SrO}$ or $\mathrm{TiO}_{2}$ surfaces. In this case, the silver was reduced uniformly on all terraces. It has also been reported that non-ferroelectric $\mathrm{SrTiO}_{3}$ can show ferroelectricity on its surface or

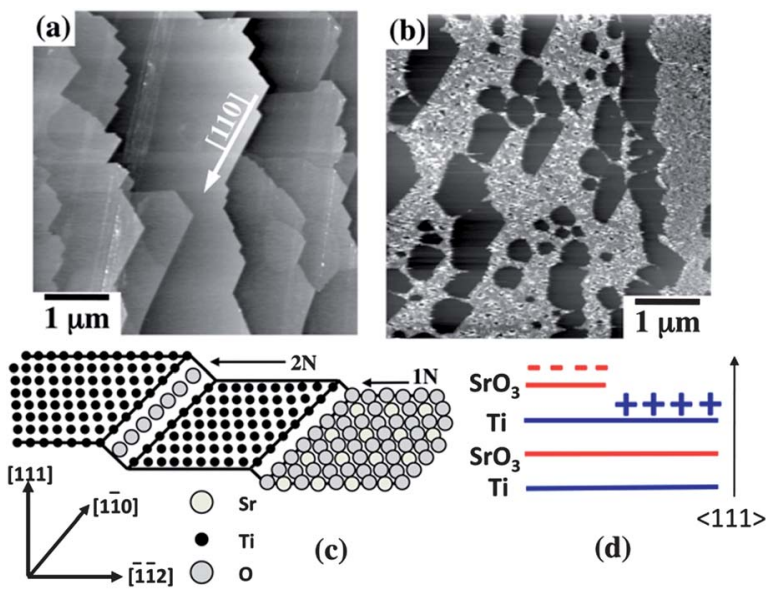

Fig. 16 The influence of dipolar field created by polar surface termination on the photochemical reactivity of $\mathrm{SrTiO}_{3}$. Topographic AFM images of the (111) surface of a $\mathrm{SrTiO}_{3}$ single crystal. (a) Before the reactions. (b) The same surface after illumination in an aqueous $\mathrm{AgNO}_{3}$ solution. The white contrast corresponds to silver. The ranges of the vertical black-to-white contrast in (a) and (b) are $60 \mathrm{~nm}$ and $200 \mathrm{~nm}$ respectively. Schematic drawing of the possible $\mathrm{SrTiO}_{3}(111)$ surface terminations. The left hand terrace has a $\mathrm{Ti}^{4+}$ termination. Traversing an even- $\mathrm{N}$ step does not change the chemical termination while traversing an odd- $\mathrm{N}$ step changes the chemical termination to $\mathrm{SrO}_{3}{ }^{4-}$ (right terrace). Note that the step edges are $\{100\}$ type. Layer spacing $(N)=\sqrt{ } 3 a / 6=1.12 \AA .43$ 
under strained/unstrained conditions. ${ }^{239-242} \quad \mathrm{SrTiO}_{3} / \mathrm{TiO}_{2}$ is reported to show higher photocatalytic activity for organic dye degradation $^{243}$ and hydrogen production than its components. ${ }^{59,244,245}$ Hierarchically structured $\mathrm{SrTiO}_{3} / \mathrm{TiO}_{2}$ nanofibers have also been used for photocatalytic water splitting. ${ }^{246}$

4.2.3. Polymorph junctions. A junction can also be formed between two different polymorphs of phases with exactly the same composition. Because the polymorphs have different structures, they also will have different electronic properties and the interaction between the phases has the potential to facilitate the separation of the photogenerated charge carriers and thus increase the photocatalytic activity. The differences in the positions of conduction band edges and band gap energies can create an internal field and thus separate charge carriers. .8,247,248 $^{2}$

For example, four different polymorphs of $\mathrm{TiO}_{2}$ have been reported, namely, anatase (tetragonal, space group $I 4_{1} / a m d$ ), rutile (tetragonal, space group $\mathrm{Pt}_{2} / \mathrm{mnm}$ ), brookite (orthorhombic, space group $\mathrm{Pbca}$ ), and $\mathrm{TiO}_{2}$ (B) (monoclinic, space group $C_{2} / m$ ). While only one of the phases is in equilibrium at a specific temperature and pressure, all four can be metastable in ambient conditions. ${ }^{74,249-253}$ Note that when heating is used to transform one phase to another, this also changes the particle size, crystallinity, porosity, and the surface $\mathrm{OH}^{-}$concentration, and all of these factors can also affect the photochemical activity ${ }^{59,79,80,254}$ The photocatalytic activity of those four phases has been compared in a number of experiments. ${ }^{255-258}$ Anatase is generally considered to be more photoactive than rutile, even though it has a relatively larger bandgap..$^{75,78,249,259}$ However, it has also been shown that if a sensitizing dye is used to inhibit recombination, the photoactivity of rutile is similar to anatase. ${ }^{77}$

It has been shown that combining titania polymorphs can lead to enhanced photocatalytic activity. One of the representative examples for this is the commercial product Degussa P25. P25 is composed of anatase and rutile and it has shown to be more photocatalytically activity than its pure phase components. ${ }^{78,260,261}$ Nanosized patches of anatase (smaller than $20 \mathrm{~nm}$ ) are supported on the surface of rutile with a larger particle size $(25-30 \mathrm{~nm})$ in P25. ${ }^{262}$ Hurum et al. investigated P25 with EPR spectroscopy and attributed the enhanced photocatalytic activity to the stabilization of charge separation by electron transfer between anatase and rutile. ${ }^{78}$ The different conduction and valance band positions lead to the formation of a potential difference between the component phases and assist the migration of charge carriers between phases. In addition, the different band gap energy and particle size also can extend the range of light absorption to the visible region and more electrons can transfer between the interface of anatase and rutile. Other mixtures of $\mathrm{TiO}_{2}$ phases also show improved photocatalytic activity for solar energy conversion. $\mathrm{TiO}_{2}$ (B) in different morphologies, such as nanofibers, coupled with anatase, has been reported to show high photocatalytic activity. ${ }^{47,249,263,264}$ Yang et al. fabricated $\mathrm{TiO}_{2}$ (B) nanofibers coated with anatase shells and the heterostructured materials were used for the degradation of the organic pollutant sulforhodamine B. ${ }^{249}$ The $\mathrm{TiO}_{2}$ (B)/anatase composite was more photocatalytically reactive than its components and had a reactivity similar to Degussa P25, as shown in Fig. $17 . \mathrm{TiO}_{2}$ (B)

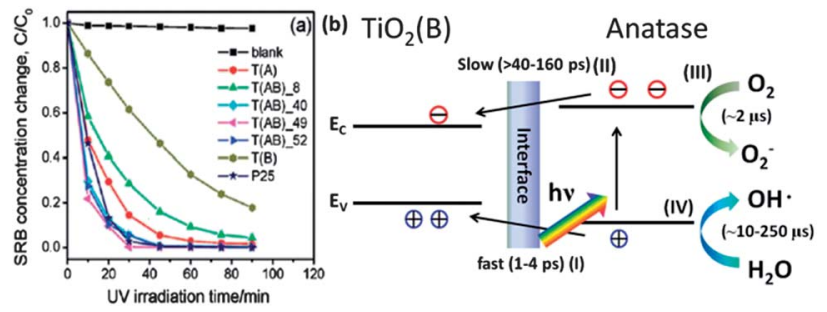

Fig. 17 (a) Photocatalytic degradation of SRB with various $\mathrm{TiO}_{2}$ photocatalysts ( $T(A)$ stands for anatase $\mathrm{TiO}_{2}, \mathrm{~T}(\mathrm{~B})$ for $\mathrm{TiO}_{2}(\mathrm{~B})$ and $\mathrm{T}(\mathrm{AB})$ for the composite of anatase and $\left.\mathrm{TiO}_{2}(\mathrm{~B})\right)$. (b) Schematic of electron-hole separation between $\mathrm{TiO}_{2}(\mathrm{~B})$ and anatase in the composite nanofibers under UV illumination (reproduced from ref. 249).

has a narrower band gap and lower conduction band position than anatase. The difference in band gap positions induces a potential difference, and part of electrons and holes from the anatase will migrate to the $\mathrm{TiO}_{2}$ (B). Because of the faster transfer rate of hole transfer (1-4 ps) to $\mathrm{TiO}_{2}$ (B) than electrons (>40-160 ps), the recombination rate of those charge carriers can be decreased for the heterostructured materials. Meanwhile, the similarity in crystallographic registry between anatase and $\mathrm{TiO}_{2}$ (B) can increase the structural stability and the operation time of the photocatalyst. Anatase coated on the surface of rutile, a configuration similar to P25, produces four times more photocatalytic $\mathrm{H}_{2}$ than pure rutile $\mathrm{TiO}_{2}{ }^{265}$ Anatase/ rutile structures with controlled microstructure and thickness were used for dye decoloration and $\mathrm{CH}_{3} \mathrm{CHO}$ oxidation. ${ }^{266,267}$ The controlled combinations of those two $\mathrm{TiO}_{2}$ polymorph junctions affected the formation of Schottky potential barriers and the charge separation distances. The enhancement of photocatalytic activity in the structures compared to their components was attributed to the transfer of photogenerated charge carriers between the different phases, which decreases recombination. Brookite and anatase composites were also found to have high photocatalytic activity, for example, for the oxidation of $\mathrm{CH}_{3} \mathrm{CHO}$, and this was also attributed to electron transfer between the phases. ${ }^{268,269}$ Anatase/brookite nanoparticle mixtures also showed higher photocatalytic hydrogen production from methanol-water solutions than anatase alone, even though the surface area was smaller. ${ }^{270}$ The combination of brookite and rutile was also confirmed to be highly effective for $\mathrm{RhB}$ photo-decolorization and its reactivity was about six times of that of $\mathrm{P} 25{ }^{271} \mathrm{~A}$ triple phase mixture of anatase, rutile and brookite also showed higher photocatalytic activity for 4-nitrophenol degradation than the single phases. ${ }^{272}$

A similar polymorphic junction was also observed for $\mathrm{Ga}_{2} \mathrm{O}_{3}$. $\mathrm{Ga}_{2} \mathrm{O}_{3}$, which is n-type, has five polymorph phases, ${ }^{273}$ of which the $\alpha-\mathrm{Ga}_{2} \mathrm{O}_{3}$ (rhombohedral) and $\beta-\mathrm{Ga}_{2} \mathrm{O}_{3}$ (monoclinic) phases are considered as more photocatalytically active for hydrogen production by water splitting, organic dye degradation, nonoxidative coupling of $\mathrm{CH}_{4}$, and the reduction of $\mathrm{CO}_{2}$ than the other phases. ${ }^{274-282} \beta-\mathrm{Ga}_{2} \mathrm{O}_{3}$ is reported to show the highest photocatalytic activity because of the long lifetime of photogenerated charge carriers in this phase, which are separated by the local internal fields induced from the coexistence of 


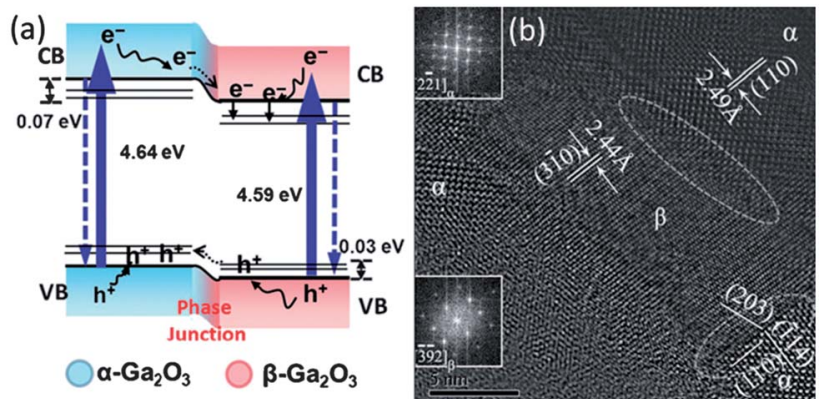

Fig. 18 (a) Illustration of $\alpha-\beta$ phase junction for charge separation and enhanced photocatalytic activity and (b) HRTEM image of the interface between $\alpha$ and $\beta-\mathrm{Ga}_{2} \mathrm{O}_{3}$ phase. (The figure is reproduced from ref. 247).

distorted tetrahedral and octahedral units. ${ }^{280}$ Wang et al. has successfully prepared $\alpha-\mathrm{Ga}_{2} \mathrm{O}_{3}$ and $\beta-\mathrm{Ga}_{2} \mathrm{O}_{3}$ junctions through the phase transformation from $\alpha-\mathrm{Ga}_{2} \mathrm{O}_{3}$ at elevated temperature. ${ }^{247}$ The $\beta$ phase is more thermally stable than the $\alpha$-phase and its fraction of the total increased with the annealing temperature. Therefore, the fraction of $\alpha-\mathrm{Ga}_{2} \mathrm{O}_{3}$ and $\beta-\mathrm{Ga}_{2} \mathrm{O}_{3}$ can be tuned by adjusting the processing temperature from 863-903 K. The $\alpha-\beta$ phase junction was prepared with wellmatched lattice fringes, as shown in Fig. 18, and showed much higher photocatalytic activity for water splitting under UV-light irradiation than the pure $\alpha$ or $\beta$ phases. The enhanced photocatalytic activity is attributed to the junction formed at the interface between two phases. The difference in the conduction band position leads to internal fields that facilitate the transfer of electrons and holes between the phases and decreases the recombination of photogenerated charge carriers.

Considering that many semiconductors are polymorphic, polymorph junctions might provide a mechanism for the efficient separation of charge carriers and, therefore, a path for increasing the efficiency of the photocatalysts. The fact that the composition on both sides of the interface is the same provides continuity of the bonding across the polymorph boundary, which may facilitate the charge transfer across the interface. The polymorph junction approach may provide a new strategy for the efficient photocatalysts design, as well as other solar energy conversion devices, such as photovoltaic and photoelectrochemical devices.

\section{Prospective and summary}

In the current review, we focused on the use of electric fields within semiconductors to separate photogenerated charge carriers and modify photocatalytic properties. Four internal field sources have been described: ferroelectric polarization, polar surfaces, $\mathrm{p}-\mathrm{n}$ junctions and polymorph junctions, as illustrated schematically in Fig. 19. The presence of the internal field changes the band bending at interfaces and provides a driving force for the separation of photogenerated electrons and holes. The distribution and direction of internal fields can be controlled so that redox reactions will occur in different places, which also decrease the back reaction of the intermediates. The manipulation of internal (a)

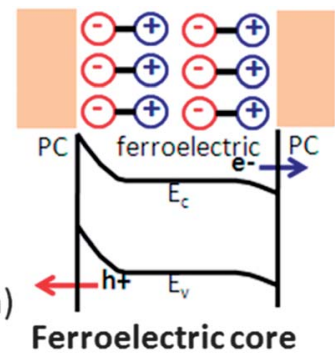

(b)
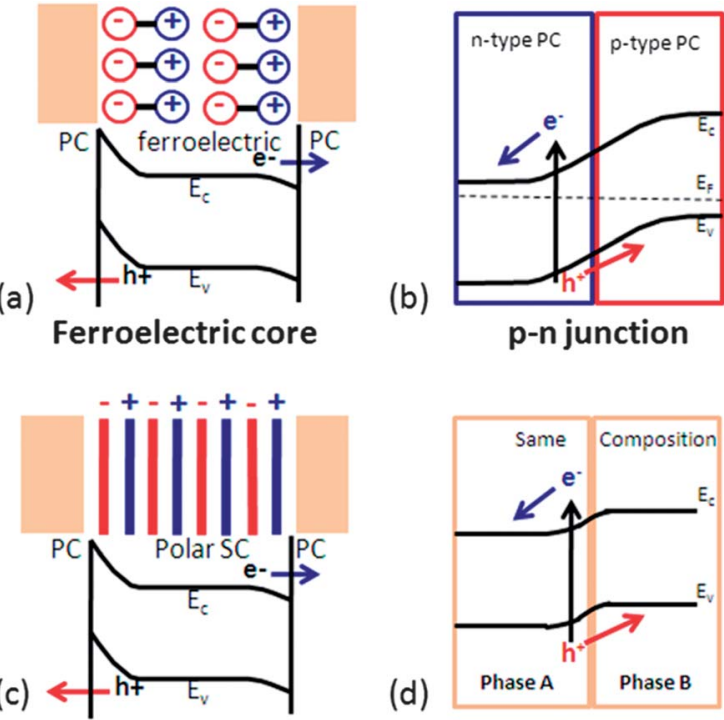

polar interfaces (d)

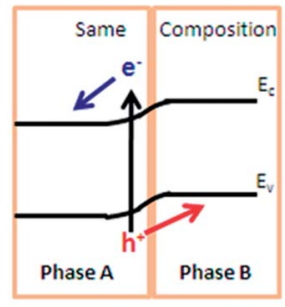

polymorph junctions

Fig. 19 The internal field enhanced photogenerated charge carrier separation: (a) ferroelectric polarization; (b) $\mathrm{p}-\mathrm{n}$ junctions; (c) polar surfaces; and (d) polymorph junctions. (PC: photocatalytic active materials; SC: semiconductor).

fields within photochemically active materials is a promising strategy for the improvement of photocatalysts.

One method for simultaneously controlling interface fields and the density of active sites is to create hierarchically structured composite materials. For example, visible light responsive materials can be coupled with materials that have internal fields and extend the performance of heterostructured photocatalysts to the visible light range. Other methods, such as doping and dye sensitization, can be combined with internal fields to design efficient visible light photocatalysts. For heterostructured photocatalysts, interface quality is important. A low defect density and chemically strong bonds across interfaces with large contact areas is preferred for electron and hole transfer. Therefore, processing techniques to engineer the interface integrity are needed. It must also be recognized that internal fields are size dependent. For example, ferroelectric polarization has been confirmed to decrease greatly below crystal sizes of about $100 \mathrm{~nm}$. On the other hand, the relationship between surface area and catalytic activity means smaller sizes are preferred for photochemical processes. Therefore, the particle size for photocatalytic materials must be selected to simultaneously optimize the positive effects of internal fields and surface area. Considering those factors, it is concluded that the manipulation of internal fields and hierarchical structures may lead to improved catalysts for water splitting and other solar energy conversion processes.

\section{Acknowledgements}

This work was supported by National Science Foundation grant DMR 1206656 and the PA DCED. 


\section{Notes and references}

1 A. Fujishima, X. Zhang and D. A. Tryk, Int. J. Hydrogen Energy, 2007, 32, 2664-2672.

2 A. Kudo, Int. J. Hydrogen Energy, 2006, 31, 197-202.

3 D. Y. C. Leung, X. L. Fu, C. F. Wang, M. Ni, M. K. H. Leung, X. X. Wang and X. Z. Fu, ChemSusChem, 2010, 3, 681694.

4 C. Chen, W. Ma and J. Zhao, Chem. Soc. Rev., 2010, 39, 42064219.

5 A. J. Esswein and D. G. Nocera, Chem. Rev., 2007, 107, 40224047.

6 A. Kudo and Y. Miseki, Chem. Soc. Rev., 2009, 38, 253-278.

7 K. Maeda, K. Teramura, D. L. Lu, T. Takata, N. Saito, Y. Inoue and K. Domen, Nature, 2006, 440, 295-295.

8 K. Maeda, K. Teramura, D. Lu, N. Saito, Y. Inoue and K. Domen, Angew. Chem., Int. Ed., 2006, 45, 7806-7809.

9 S. Y. Reece, J. A. Hamel, K. Sung, T. D. Jarvi, A. J. Esswein, J. J. H. Pijpers and D. G. Nocera, Science, 2011, 334, 645-648.

10 H. Kato, K. Asakura and A. Kudo, J. Am. Chem. Soc., 2003, 125, 3082-3089.

11 J. F. Reber and K. Meier, J. Phys. Chem., 1984, 88, 5903-5913.

12 X. Chen, L. Liu, P. Y. Yu and S. S. Mao, Science, 2011, 331, 746-750.

13 R. Asahi, T. Morikawa, T. Ohwaki, K. Aoki and Y. Taga, Science, 2001, 293, 269-271.

14 Z. G. Zou, J. H. Ye, K. Sayama and H. Arakawa, Nature, 2001, 414, 625-627.

15 Y. Inoue, Energy Environ. Sci., 2009, 2, 364-386.

16 D. Tiwari and S. Dunn, J. Mater. Sci., 2009, 44, 5063-5079.

17 Z. Zhang and J. T. Yates, Chem. Rev., 2012, 112, 5520-5551.

18 F. E. Osterloh, Chem. Mater., 2008, 20, 35-54.

19 F. E. Osterloh, Chem. Soc. Rev., 2013, 42, 2294-2320.

20 X. Chen, S. Shen, L. Guo and S. S. Mao, Chem. Rev., 2010, 110, 6503-6570.

21 X. Chen, C. Li, M. Gratzel, R. Kostecki and S. S. Mao, Chem. Soc. Rev., 2012, 41, 7909-7937.

22 G. N. Schrauzer and T. D. Guth, J. Am. Chem. Soc., 1977, 99, 7189-7193.

23 B. Kraeutler and A. J. Bard, J. Am. Chem. Soc., 1978, 100, 4317-4318.

24 K. Masao and O. Ichiro, Photocatalysis Science and Technology, Springer, 2002.

25 D. A. Tryk, A. Fujishima and K. Honda, Electrochim. Acta, 2000, 45, 2363-2376.

26 K. Domen, in Surface Photochemistry, ed. M. Anpo, J. Wiley \& Sons, Chichester, 1996, pp. 1-18.

27 W. J. Albery and N. B. Philip, J. Electrochem. Soc., 1984, 131, 315-325.

28 M. D. Hernandez-Alonso, F. Fresno, S. Suarez and J. M. Coronado, Energy Environ. Sci., 2009, 2, 1231-1257.

29 K. Maeda and K. Domen, J. Phys. Chem. Lett., 2010, 1, 26552661.

30 M. C. A. G. Rufino, M. Navarro Yerga, F. del Valle, J. A. Villoria de la Mano and J. L. G. Fierro, ChemSusChem, 2009, 2, 471-485.
31 U. A. Joshi, A. Palasyuk, D. Arney and P. A. Maggard, J. Phys. Chem. Lett., 2010, 1, 2719-2726.

32 T. Tachikawa, M. Fujitsuka and T. Majima, J. Phys. Chem. C, 2007, 111, 5259-5275.

33 K. Rajeshwar, J. Appl. Electrochem., 2007, 37, 765-787.

34 K. Maeda, K. Teramura, D. L. Lu, T. Takata, N. Saito, Y. Inoue and K. Domen, J. Phys. Chem. B, 2006, 110, 13753-13758.

35 K. Maeda, T. Takata, M. Hara, N. Saito, Y. Inoue, H. Kobayashi and K. Domen, J. Am. Chem. Soc., 2005, 127, 8286-8287.

36 S. R. Morrison, Electrochemistry at semiconductor and oxidized metal electrodes, Plenum Press, New York, 1980.

37 A. L. Linsebigler, G. Lu and J. T. Yates, Chem. Rev., 1995, 95, 735-758.

38 A. J. Nozik and R. Memming, J. Phys. Chem., 1996, 100, 13061-13078.

39 J. Yang, D. Wang, H. Han and C. Li, Acc. Chem. Res., 2013, 46, 1900-1909.

40 P. V. Kamat, J. Phys. Chem. Lett., 2012, 3, 663-672.

41 W. Wang, X. Huang, S. Wu, Y. Zhou, L. Wang, H. Shi, Y. Liang and B. Zou, Appl. Catal., B, 2013, 134-135, 293-301.

42 X. Lin, J. Xing, W. Wang, Z. Shan, F. Xu and F. Huang, J. Phys. Chem. C, 2007, 111, 18288-18293.

43 J. L. Giocondi and G. S. Rohrer, J. Am. Ceram. Soc., 2003, 86, 1182-1189.

44 Y. Matsumoto, T. Ohsawa, R. Takahashi and H. Koinuma, Thin Solid Films, 2005, 486, 11-14.

45 N. Kislov, J. Lahiri, H. Verma, D. Y. Goswami, E. Stefanakos and M. Batzill, Langmuir, 2009, 25, 3310-3315.

46 G. Liu, J. C. Yu, G. Q. Lu and H.-M. Cheng, Chem. Commun., 2011, 47, 6763-6783.

47 W. Li, C. Liu, Y. Zhou, Y. Bai, X. Feng, Z. Yang, L. Lu, X. Lu and K.-Y. Chan, J. Phys. Chem. C, 2008, 112, 20539-20545.

48 G. Tian, H. Fu, L. Jing, B. Xin and K. Pan, J. Phys. Chem. C, 2008, 112, 3083-3089.

49 J. L. Giocondi and G. S. Rohrer, Top. Catal., 2008, 49, 18-23.

50 L. Li, Y. Zhang, A. M. Schultz, X. Liu, P. A. Salvador and G. S. Rohrer, Catal. Sci. Technol., 2012, 2, 1945-1952.

51 Y. Gou, D. Chen and Z. Su, Appl. Catal., A, 2004, 261, 15-18. 52 R. Qiu, D. Zhang, Y. Mo, L. Song, E. Brewer, X. Huang and Y. Xiong, J. Hazard. Mater., 2008, 156, 80-85.

53 H.-C. Liang and X.-Z. Li, Appl. Catal., B, 2009, 86, 8-17.

54 K. Hashimoto, H. Irie and A. Fujishima, Jpn. J. Appl. Phys., 2005, 44, 8269-8285.

55 M. Kitano and M. Hara, J. Mater. Chem., 2010, 20, 627-641. 56 J. F. Reber and M. Rusek, J. Phys. Chem., 1986, 90, 824-834.

57 N. Buhler, K. Meier and J. F. Reber, J. Phys. Chem., 1984, 88, 3261-3268.

58 L. Li, G. S. Rohrer and P. A. Salvador, J. Am. Ceram. Soc., 2012, 95, 1414-1420.

59 L. Li, X. Liu, Y. Zhang, P. A. Salvador and G. S. Rohrer, Int. J. Hydrogen Energy, 2013, 38, 6948-6959.

60 S. E. Stanca, R. Muller, M. Urban, A. Csaki, F. Froehlich, C. Krafft, J. Popp and W. Fritzsche, Catal. Sci. Technol., 2012, 2, 1472-1479. 
61 Z. Zhang, C.-C. Wang, R. Zakaria and J. Y. Ying, J. Phys. Chem. B, 1998, 102, 10871-10878.

62 D. Beydoun, R. Amal, G. Low and S. McEvoy, J. Nanopart. Res., 1999, 1, 439-458.

63 A. Bhardwaj, N. V. Burbure, A. Gamalski and G. S. Rohrer, Chem. Mater., 2010, 22, 3527-3534.

64 W. J. Albery and P. N. Bartlett, J. Electrochem. Soc., 1984, 131, 315-325.

65 U. Banin, Y. W. Cao, D. Katz and O. Millo, Nature, 1999, 400, 542-544.

66 X. G. Peng, L. Manna, W. D. Yang, J. Wickham, E. Scher, A. Kadavanich and A. P. Alivisatos, Nature, 2000, 404, 59-61.

67 Y. Wang and N. Herron, J. Phys. Chem., 1991, 95, 525-532.

68 J. Pan, G. Liu, G. Q. Lu and H.-M. Cheng, Angew. Chem., Int. Ed., 2011, 50, 2133-2137.

69 G. Liu, C. Sun, H. G. Yang, S. C. Smith, L. Wang, G. Q. M. Lu and H.-M. Cheng, Chem. Commun., 2010, 46, 755-757.

70 J. Giocondi, P. Salvador and G. Rohrer, Top. Catal., 2007, 44, 529-533.

71 R. Li, F. Zhang, D. Wang, J. Yang, M. Li, J. Zhu, X. Zhou, H. Han and C. Li, Nat. Commun., 2013, 4, 1432.

72 W. E. Farneth, R. S. McLean, J. D. Bolt, E. Dokou and M. A. Barteau, Langmuir, 1999, 15, 8569-8573.

73 P. A. Morris Hotsenpiller, J. D. Bolt, W. E. Farneth, J. B. Lowekamp and G. S. Rohrer, J. Phys. Chem. B, 1998, 102, 3216-3226.

74 H. Z. Zhang and J. F. Banfield, J. Phys. Chem. B, 2000, 104, 3481-3487.

75 A. Sclafani and J. M. Herrmann, J. Phys. Chem., 1996, 100, 13655-13661.

76 L. Kavan, M. Grätzel, S. E. Gilbert, C. Klemenz and H. J. Scheel, J. Am. Chem. Soc., 1996, 118, 6716-6723.

77 N. G. Park, J. van de Lagemaat and A. J. Frank, J. Phys. Chem. $B$, 2000, 104, 8989-8994.

78 D. C. Hurum, A. G. Agrios, K. A. Gray, T. Rajh and M. C. Thurnauer, J. Phys. Chem. B, 2003, 107, 4545-4549.

79 C. K. Chan, J. F. Porter, Y. G. Li, W. Guo and C. M. Chan, J. Am. Ceram. Soc., 1999, 82, 566-572.

80 Q. H. Zhang, L. Gao and J. K. Guo, Appl. Catal., B, 2000, 26, 207-215.

81 L. Gao and Q. H. Zhang, Scr. Mater., 2001, 44, 1195-1198.

82 R. M. Noyes, J. Am. Chem. Soc., 1962, 84, 513-522.

83 S. Trasatti, J. Electroanal. Chem., 1974, 52, 313-329.

84 W. N. Hansen and D. M. Kolb, J. Electroanal. Chem., 1979, 100, 493-500.

85 M. A. Butler and D. S. Ginley, J. Electrochem. Soc., 1978, 125, 228-232.

86 A. J. Nozik, Annu. Rev. Phys. Chem., 1978, 29, 189-222.

87 H. Luth, Solid Surfaces, Interfaces and Thin Films, Springer Berlin Heidelberg, New York, 2010.

88 M. Gratzel, Nature, 2001, 414, 338-344.

89 T. Bak, J. Nowotny, M. Rekas and C. C. Sorrell, J. Phys. Chem. Solids, 2003, 64, 1043-1056.

90 M. K. Nowotny, T. Bak and J. Nowotny, J. Phys. Chem. B, 2006, 110, 16270-16282.

91 J. Liqiang, S. Xiaojun, S. Jing, C. Weimin, X. Zili, D. Yaoguo and F. Honggang, Sol. Energy Mater. Sol. Cells, 2003, 79, 133-151.
92 W. Monch, Electronic Properties of Semiconductor Interfaces, Springer-Verlag, New York, 2004.

93 A. Fujishima, T. N. Rao and D. A. Tryk, J. Photochem. Photobiol., C, 2000, 1, 1-21.

94 A. Beer, Phys. Chem., 1852, 86, 78.

95 H. A. Liebhafsky and H. G. Pfeiffer, J. Chem. Educ., 1953, 30, 450.

96 H. Tang, F. Levy, H. Berger and P. E. Schmid, Phys. Rev. B: Condens. Matter Mater. Phys., 1995, 52, 7771-7774.

97 Y. R. Park and K. J. Kim, Thin Solid Films, 2005, 484, 34-38.

98 S. P. Albu, A. Ghicov, J. M. Macak, R. Hahn and P. Schmuki, Nano Lett., 2007, 7, 1286-1289.

99 N. V. Burbure, P. A. Salvador and G. S. Rohrer, J. Am. Ceram. Soc., 2006, 89, 2943-2945.

100 A. J. Nozik, Appl. Phys. Lett., 1977, 30, 567-569.

101 J. L. Giocondi and G. S. Rohrer, J. Phys. Chem. B, 2001, 105, 8275-8277.

102 J. L. Giocondi and G. S. Rohrer, Chem. Mater., 2001, 13, 241242.

103 K. M. Rabe, C. H. Ahn and J.-M. Triscone, Physics of Ferroelectrics: A Modern Perspective, Springer, 2007.

104 M. E. Lines and A. M. Glass, Principles and applications of ferroelectrics and related materials, Clarendon Press, Oxford, 1977.

105 D. Damjanovic, Rep. Prog. Phys., 1998, 61, 1267-1324.

106 C. H. Ahn, K. M. Rabe and J. M. Triscone, Science, 2004, 303, 488-491.

107 M. E. Lines and A. M. Glass, Principles and Applications of Ferroelectrics and Related Materials, Clarendon Press, Oxford, 2001.

108 N. Braithwaite and G. Weaver, Materials in action series electronic materials inside electronic devices, Alden Press (London \& Northampton) Ltd, London, 1998.

109 T. Mitsui, I. Tatsuzaki and E. Nakamura, An Introduction to the Physics of Ferroelectris, Gordon and Breach Science Publishers, 1976.

110 E. K. Akdogan, C. J. Rawn, W. D. Porter, E. A. Payzant and A. Safari, J. Appl. Phys., 2005, 97, 084305.

111 M. Yashima, T. Hoshina, D. Ishimura, S. Kobayashi, W. Nakamura, T. Tsurumi and S. Wada, J. Appl. Phys., 2005, 98, 014313.

112 K. Uchino, E. Sadanaga and T. Hirose, J. Am. Ceram. Soc., 1989, 72, 1555-1558.

113 X. P. Li and W. H. Shih, J. Am. Ceram. Soc., 1997, 80, 2844-2852. 114 Naumov II, L. Bellaiche and H. X. Fu, Nature, 2004, 432, 737-740.

115 M. J. Polking, M.-G. Han, A. Yourdkhani, V. Petkov, C. F. Kisielowski, V. V. Volkov, Y. Zhu, G. Caruntu, A. Paul Alivisatos and R. Ramesh, Nat. Mater., 2012, 11, 700-709.

116 L. Zhang, W. L. Zhong, C. L. Wang, Y. P. Peng and Y. G. Wang, Eur. Phys. J. B, 1999, 11, 565-573.

117 A. M. Glass, D. von der Linde and T. J. Negran, Appl. Phys. Lett., 1974, 25, 233-235.

118 O. Ambacher, J. Smart, J. R. Shealy, N. G. Weimann, K. Chu, M. Murphy, W. J. Schaff, L. F. Eastman, R. Dimitrov, L. Wittmer, M. Stutzmann, W. Rieger and J. Hilsenbeck, J. Appl. Phys., 1999, 85, 3222-3233. 
119 R. C. Casella and S. P. Keller, Phys. Rev., 1959, 116, 1469-1473. 120 M. Cardona, Phys. Rev., 1965, 140, A651-A655.

121 H. H. Kung, H. S. Jarrett, A. W. Sleight and A. Ferretti, J. Appl. Phys., 1977, 48, 2463-2469.

122 C. N. Berglund and H. J. Braun, Phys. Rev., 1967, 164, 790. 123 A. J. Bard and L. R. Faulkner, Electrochemical methods: fundamentals and applications, John Wiley \& Sons, Inc., New York, 2001.

124 Y. Inoue, K. Sato, K. Sato and H. Miyama, J. Phys. Chem., 1986, 90, 2809-2810.

125 P. M. Jones, D. E. Gallardo and S. Dunn, Chem. Mater., 2008, 20, 5901-5906.

126 S. Dunn, P. M. Jones and D. E. Gallardo, J. Am. Chem. Soc., 2007, 129, 8724-8728.

127 P. M. Jones and S. Dunn, Nanotechnology, 2007, 18, 185702. 128 S. Dunn, S. Sharp and S. Burgess, Nanotechnology, 2009, 20, 115604.

129 P. M. Jones and S. Dunn, J. Phys. D: Appl. Phys., 2009, 42, 065408.

130 S. V. Kalinin, D. A. Bonnell, T. Alvarez, X. Lei, Z. Hu, J. H. Ferris, Q. Zhang and S. Dunn, Nano Lett., 2002, 2, 589-593.

131 J. Chen, H. Lu, H.-J. Liu, Y.-H. Chu, S. Dunn, A. Gruverman and N. Valanoor, Appl. Phys. Lett., 2013, 102, 182904.

132 X. Liu, K. Kitamura, K. Terabe, H. Hatano and N. Ohashi, Appl. Phys. Lett., 2007, 91, 044101.

133 M. Stock and S. Dunn, J. Phys. Chem. C, 2012, 116, 2085420859.

134 A. M. Schultz, Y. Zhang, P. A. Salvador and G. S. Rohrer, ACS Appl. Mater. Interfaces, 2012, 3, 1562-1567.

135 Z. Liu, Y. Qi and C. Lu, J. Mater. Sci.: Mater. Electron., 2010, 21, 380-384.

136 F. Gao, X. Y. Chen, K. B. Yin, S. Dong, Z. F. Ren, F. Yuan, T. Yu, Z. Zou and J. M. Liu, Adv. Mater., 2007, 19, 2889-2892.

137 X. Lu, J. Xie, Y. Song and J. Lin, J. Mater. Sci., 2007, 42, 68246827.

138 C. M. Cho, J. H. Noh, I. S. Cho, J. S. An, K. S. Hong and J. Y. Kim, J. Am. Ceram. Soc., 2008, 91, 3753-3755.

139 S. Li, Y.-H. Lin, B.-P. Zhang, C.-W. Nan and Y. Wang, J. Appl. Phys., 2009, 105, 056105.

140 S. Li, Y.-H. Lin, B.-P. Zhang, Y. Wang and C.-W. Nan, J. Phys. Chem. C, 2010, 114, 2903-2908.

141 H. van Damme and W. K. Hall, J. Catal., 1981, 69, 371-383.

142 K. Domen, A. Kudo, A. Shinozaki, A. Tanaka, K. Maruya and T. Onishi, J. Chem. Soc., Chem. Commun., 1986, 356-357.

143 Q. Wu, D. Li, L. Wu, J. Wang, X. Fu and X. Wang, J. Mater. Chem., 2006, 16, 1116-1117.

144 Y. Inoue, I. Yoshioka and K. Sato, J. Phys. Chem., 1984, 88, 1148-1151.

145 A. Kudo, A. Tanaka, K. Domen, K. Maruya, K. Aika and T. Onishi, J. Catal., 1988, 111, 67-76.

146 Y. Inoue, K. Sato and K. Sato,J. Chem. Soc., Faraday Trans. 1, 1989, 85, 1765-1774.

147 T. Takata, Y. Furumi, K. Shinohara, A. Tanaka, M. Hara, J. N. Kondo and K. Domen, Chem. Mater., 1997, 9, 1063-1064.

148 S. Ikeda, M. Hara, J. N. Kondo, K. Domen, H. Takahashi, T. Okubo and M. Kakihana, Chem. Mater., 1998, 10, 72-77.
149 A. Kudo, H. Kato and S. Nakagawa, J. Phys. Chem. B, 1999, 104, 571-575.

150 H. G. Kim, O. S. Becker, J. S. Jang, S. M. Ji, P. H. Borse and J. S. Lee, J. Solid State Chem., 2006, 179, 1214-1218.

151 Y. Inoue, M. Okamura and K. Sato, J. Phys. Chem., 1985, 89, 5184-5187.

152 Y. Inoue, K. Sato and S. Suzuki, J. Phys. Chem., 1985, 89, 2827-2831.

153 N. V. Burbure, P. A. Salvador and G. S. Rohrer, Chem. Mater., 2010, 22, 5831-5837.

154 N. V. Burbure, P. A. Salvador and G. S. Rohrer, Chem. Mater., 2010, 22, 5823-5830.

155 Y. Zhang, A. M. Schultz, P. A. Salvador and G. S. Rohrer, J. Mater. Chem., 2011, 21, 4168-4174.

156 H. J. Huang, D. Z. Li, Q. Lin, Y. Shao, W. Chen, Y. Hu, Y. B. Chen and X. Z. Fu, J. Phys. Chem. C, 2009, 113, 14264-14269.

157 Q. Li, R. Li, L. Zong, J. He, X. Wang and J. Yang, Int. J. Hydrogen Energy, 2013, 38, 12977-12983.

158 S. Li, Y. H. Lin, B. P. Zhang, J. F. Li and C. W. Nan, J. Appl. Phys., 2009, 105, 054310.

159 O. Ruzimuradov, G. Hasegawa, K. Kanamori and K. Nakanishi, J. Am. Ceram. Soc., 2011, 94, 3335-3339.

160 J. J. Loferski, J. Appl. Phys., 1956, 27, 777-784.

161 F. Huber, J. Electrochem. Soc., 1963, 110, 846-847.

162 R. L. Cummerow, Phys. Rev., 1954, 95, 16-21.

163 B. Parida, S. Iniyan and R. Goic, Renewable Sustainable Energy Rev., 2011, 15, 1625-1636.

164 M. A. Green, Englewood Cliffs, Prentice-Hall, Inc., NJ, 1982, vol. 1, p. 288.

165 A. Shah, P. Torres, R. Tscharner, N. Wyrsch and H. Keppner, Science, 1999, 285, 692-698.

166 A. Goetzberger, C. Hebling and H. W. Schock, Mater. Sci. Eng., $R$, 2003, 40, 1-46.

167 P. V. Kamat, K. Tvrdy, D. R. Baker and J. G. Radich, Chem. Rev., 2010, 110, 6664-6688.

168 O. Khaselev and J. A. Turner, Science, 1998, 280, 425-427.

169 R. G. Breckenridge and W. R. Hosler, Phys. Rev., 1953, 91, 793.

170 M. K. Nowotny, P. Bogdanoff, T. Dittrich, S. Fiechter, A. Fujishima and H. Tributsch, Mater. Lett., 2010, 64, 928-930.

171 L. Yang, S. Luo, Y. Li, Y. Xiao, Q. Kang and Q. Cai, Environ. Sci. Technol., 2010, 44, 7641-7646.

172 Y. Bessekhouad, D. Robert and J. V. Weber, Catal. Today, 2005, 101, 315-321.

173 K. Lalitha, G. Sadanandam, V. D. Kumari, M. Subrahmanyam, B. Sreedhar and N. Y. Hebalkar, J. Phys. Chem. C, 2010, 114, 22181-22189.

174 D. Barreca, G. Carraro, A. Gasparotto, C. Maccato, O. I. Lebedev, A. Parfenova, S. Turner, E. Tondello and G. Van Tendeloo, Langmuir, 2011, 27, 6409-6417.

175 T.-Y. Tsai, S.-J. Chang, T.-J. Hsueh, H.-T. Hsueh, W.-Y. Weng, C.-L. Hsu and B.-T. Dai, Nanoscale Res. Lett., 2011, 6, 1-7.

176 D. Sarkar, C. K. Ghosh, S. Mukherjee and K. K. Chattopadhyay, ACS Appl. Mater. Interfaces, 2013, 5, 331-337. 
177 W. Zhou, H. Liu, J. Wang, D. Liu, G. Du and J. Cui, ACS Appl. Mater. Interfaces, 2010, 2, 2385-2392.

178 W. Zhou, H. Liu, J. Wang, D. Liu, G. Du, S. Han, J. Lin and R. Wang, Phys. Chem. Chem. Phys., 2010, 12, 15119-15123.

179 G. Dai, S. Liu, Y. Liang and T. Luo, Appl. Surf. Sci., 2012, 264, 157-161.

180 R. Brahimi, Y. Bessekhouad, A. Bouguelia and M. Trari, J. Photochem. Photobiol., A, 2007, 186, 242-247.

181 L. Wei, C. Shifu, Z. Sujuan, Z. Wei, Z. Huaye and Y. Xiaoling, J. Nanopart. Res., 2010, 12, 1355-1366.

182 C. Shifu, Z. Sujuan, L. Wei and Z. Wei, J. Hazard. Mater., 2008, 155, 320-326.

183 L. C. Sim, K. W. Ng, S. Ibrahim and P. Saravanan, Int. J. Photoenergy, 2013, 2013, 10.

184 X. Zhang, L. Zhang, T. Xie and D. Wang, J. Phys. Chem. C, 2009, 113, 7371-7378.

185 X. Zhang, Z. Ai, F. Jia and L. Zhang, J. Phys. Chem. C, 2008, 112, 747-753.

186 G. Dai, J. Yu and G. Liu, J. Phys. Chem. C, 2011, 115, 7339-7346.

187 Y. J. Kim, B. Gao, S. Y. Han, M. H. Jung, A. K. Chakraborty, T. Ko, C. Lee and W. I. Lee, J. Phys. Chem. C, 2009, 113, 19179-19184.

188 B. Gao, Y. J. Kim, A. K. Chakraborty and W. I. Lee, Appl. Catal., B, 2008, 83, 202-207.

189 S. Gilje, S. Han, M. Wang, K. L. Wang and R. B. Kaner, Nano Lett., 2007, 7, 3394-3398.

190 C. Chen, W. Cai, M. Long, B. Zhou, Y. Wu, D. Wu and Y. Feng, ACS Nano, 2010, 4, 6425-6432.

191 F. Wang and K. Zhang, J. Mol. Catal. A: Chem., 2011, 345, 101-107.

192 J. Liu, H. Bai, Y. Wang, Z. Liu, X. Zhang and D. D. Sun, Adv. Funct. Mater., 2010, 20, 4175-4181.

193 G. Jiang, Z. Lin, C. Chen, L. Zhu, Q. Chang, N. Wang, W. Wei and H. Tang, Carbon, 2011, 49, 2693-2701.

194 Z. Zhang, C. Shao, X. Li, C. Wang, M. Zhang and Y. Liu, ACS Appl. Mater. Interfaces, 2010, 2, 2915-2923.

195 C. Shifu, Z. Wei, L. Wei, Z. Huaye, Y. Xiaoling and C. Yinghao, J. Hazard. Mater., 2009, 172, 1415-1423.

196 M. Long, W. Cai, J. Cai, B. Zhou, X. Chai and Y. Wu, J. Phys. Chem. B, 2006, 110, 20211-20216.

197 C. Long and H. Kisch, J. Phys. Chem. C, 2007, 112, 548-554. 198 T. Arai, M. Yanagida, Y. Konishi, Y. Iwasaki, H. Sugihara and K. Sayama, J. Phys. Chem. C, 2007, 111, 7574-7577.

199 J. Cao, X. Li, H. Lin, S. Chen and X. Fu, J. Hazard. Mater., 2012, 239-240, 316-324.

200 L. Chen, S.-F. Yin, S.-L. Luo, R. Huang, Q. Zhang, T. Hong and P. C. T. Au, Ind. Eng. Chem. Res., 2012, 51, 6760-6768.

201 L. Wei and C. Shifu, J. Electrochem. Soc., 2010, 157, H1029H1035.

202 C.-C. Hu, J.-N. Nian and H. Teng, Sol. Energy Mater. Sol. Cells, 2008, 92, 1071-1076.

203 H. Lin, H. Ye, B. Xu, J. Cao and S. Chen, Catal. Commun., 2013, 37, 55-59.

204 H. G. Kim, P. H. Borse, W. Choi and J. S. Lee, Angew. Chem., 2005, 117, 4661-4665.

205 A. R. Bally, E. N. Korobeinikova, P. E. Schmid, F. Levy and F. Bussy, J. Phys. D: Appl. Phys., 1998, 31, 1149.
206 J. Chen, P. Rulis, L. Ouyang, S. Satpathy and W. Y. Ching, Phys. Rev. B: Condens. Matter Mater. Phys., 2006, 74, 235207.

207 Y. Li, W. Wlodarski, K. Galatsis, S. H. Moslih, J. Cole, S. Russo and N. Rockelmann, Sens. Actuators, B, 2002, 83, 160-163.

208 A. Ruiz, A. Cornet, G. Sakai, K. Shimanoe, J. R. Morante and N. Yamazoe, Chem. Lett., 2002, 31, 892-893.

209 C. Shifu, L. Wei, Z. Sujuan and C. Yinghao, J. Sol-Gel Sci. Technol., 2010, 54, 258-267.

210 C. Kim, K.-S. Kim, H. Y. Kim and Y. S. Han, J. Mater. Chem., 2008, 18, 5809-5814.

211 P. T. Moseley and D. E. Williams, Polyhedron, 1989, 8, 16151618.

212 A. M. Ruiz, G. Sakai, A. Cornet, K. Shimanoe, J. R. Morante and N. Yamazoe, Sens. Actuators, B, 2003, 93, 509-518.

213 S. Liu, T. Xie, Z. Chen and J. Wu, Appl. Surf. Sci., 2009, 255, 8587-8592.

214 D. J. Mowbray, J. I. Martinez, J. M. Garcia Lastra, K. S. Thygesen and K. W. Jacobsen, J. Phys. Chem. C, 2009, 113, 12301-12308.

215 D. Wang, Y. Zou, S. Wen and D. Fan, Appl. Phys. Lett., 2009, 95, 012106.

216 C. Shifu, Y. Xiaoling, Z. Huaye and L. Wei, J. Electrochem. Soc., 2010, 157, K96-K102.

217 J. Zhang, X. Tang and D. Li, J. Phys. Chem. C, 2011, 115, 21529-21534.

218 S.-H. Wei, Comput. Mater. Sci., 2004, 30, 337-348.

219 J. Li, S.-H. Wei, S.-S. Li and J.-B. Xia, Phys. Rev. B: Condens. Matter Mater. Phys., 2006, 74, 081201.

220 D. J. Chadi, Phys. Rev. B: Condens. Matter Mater. Phys., 1999, 59, 15181-15183.

221 A. Garcia and J. E. Northrup, Phys. Rev. Lett., 1995, 74, 11311134.

222 P. J. George, A. Sanchez, P. K. Nair and M. T. S. Nair, Appl. Phys. Lett., 1995, 66, 3624-3626.

223 S.-H. Wei and S. B. Zhang, Phys. Rev. B: Condens. Matter Mater. Phys., 2002, 66, 155211.

224 Y. Lin, Y. Xu, M. T. Mayer, Z. I. Simpson, G. McMahon, S. Zhou and D. Wang, J. Am. Chem. Soc., 2012, 134, 55085511.

225 W. Wang, D. Wu, Q. Zhang, L. Wang and M. Tao, J. Appl. Phys., 2010, 107, 123717.

226 C. M. McShane and K.-S. Choi, J. Am. Chem. Soc., 2009, 131, 2561-2569.

227 H. M. Wei, H. B. Gong, L. Chen, M. Zi and B. Q. Cao, J. Phys. Chem. C, 2012, 116, 10510-10515.

228 T. Jiang, T. Xie, W. Yang, L. Chen, H. Fan and D. Wang, J. Phys. Chem. C, 2013, 117, 4619-4624.

229 P. A. Sant and P. V. Kamat, Phys. Chem. Chem. Phys., 2002, 4, 198-203.

230 B. Jiang, S. Zhang, X. Guo, B. Jin and Y. Tian, Appl. Surf. Sci., 2009, 255, 5975-5978.

231 I. Robel, M. Kuno and P. V. Kamat, J. Am. Chem. Soc., 2007, 129, 4136-4137.

232 L. Li, X. Liu, Y. Zhang, N. T. Nuhfer, K. Barmak, P. A. Salvador and G. S. Rohrer, ACS Appl. Mater. Interfaces, 2013, 5, 5064-5071. 
233 J. Yu, W. Wang and B. Cheng, Chem.-Asian J., 2010, 5, 24992506.

234 X. Li, R. Huang, Y. Hu, Y. Chen, W. Liu, R. Yuan and Z. Li, Inorg. Chem., 2012, 51, 6245-6250.

235 J. Lin, J. Shen, R. Wang, J. Cui, W. Zhou, P. Hu, D. Liu, H. Liu, J. Wang, R. I. Boughton and Y. Yue, J. Mater. Chem., 2011, 21, 5106-5113.

236 Y. Li, J. Gong and Y. Deng, Sens. Actuators, A, 2010, 158, 176-182.

237 M. Deo, D. Shinde, A. Yengantiwar, J. Jog, B. Hannoyer, X. Sauvage, M. More and S. Ogale, J. Mater. Chem., 2012, 22, 17055-17062.

238 W. Hebenstreit, M. Schmid, J. Redinger, R. Podloucky and P. Varga, Phys. Rev. Lett., 2000, 85, 5376-5379.

239 N. Bickel, G. Schmidt, K. Heinz and K. Muller, Phys. Rev. Lett., 1989, 62, 2009.

240 J. H. Haeni, P. Irvin, W. Chang, R. Uecker, P. Reiche, Y. L. Li, S. Choudhury, W. Tian, M. E. Hawley, B. Craigo, A. K. Tagantsev, X. Q. Pan, S. K. Streiffer, L. Q. Chen, S. W. Kirchoefer, J. Levy and D. G. Schlom, Nature, 2004, 430, 758-761.

241 H. W. Jang, A. Kumar, S. Denev, M. D. Biegalski, P. Maksymovych, C. W. Bark, C. T. Nelson, C. M. Folkman, S. H. Baek, N. Balke, C. M. Brooks, D. A. Tenne, D. G. Schlom, L. Q. Chen, X. Q. Pan, S. V. Kalinin, V. Gopalan and C. B. Eom, Phys. Rev. Lett., 2010, 104, 197601.

242 Y. S. Kim, D. J. Kim, T. H. Kim, T. W. Noh, J. S. Choi, B. H. Park and J. G. Yoon, Appl. Phys. Lett., 2007, 91, 042908.

243 T. P. Cao, Y. J. Li, C. H. Wang, C. L. Shao and Y. C. Liu, Langmuir, 2011, 27, 2946-2952.

244 J.-H. Yan, Y.-R. Zhu, Y.-G. Tang and S.-Q. Zheng, J. Alloys Compd., 2009, 472, 429-433.

245 H. Bai, Z. Liu and D. D. Sun, J. Am. Ceram. Soc., 2012, 96, 942-949.

246 H. Bai, J. Juay, Z. Liu, X. Song, S. S. Lee and D. D. Sun, Appl. Catal., B, 2012, 125, 367-374.

247 X. Wang, Q. Xu, M. Li, S. Shen, X. Wang, Y. Wang, Z. Feng, J. Shi, H. Han and C. Li, Angew. Chem., Int. Ed., 2012, 51, 13089-13092.

248 R. Hengerer, L. Kavan, P. Krtil and M. Gratzel, J. Electrochem. Soc., 2000, 147, 1467-1472.

249 D. Yang, H. Liu, Z. Zheng, Y. Yuan, J.-C. Zhao, E. R. Waclawik, X. Ke and H. Zhu, J. Am. Chem. Soc., 2009, 131, 17885-17893.

250 S. Bakardjieva, V. Stengl, L. Szatmary, J. Subrt, J. Lukac, N. Murafa, D. Niznansky, K. Cizek, J. Jirkovsky and N. Petrova, J. Mater. Chem., 2006, 16, 1709-1716.

251 B. Ohtani, Y. Ogawa and S.-i. Nishimoto, J. Phys. Chem. B, 1997, 101, 3746-3752.

252 R. A. Spurr and H. Myers, Anal. Chem., 1957, 29, 760-762.

253 P. I. Gouma and M. J. Mills, J. Am. Ceram. Soc., 2001, 84, 619-622.

254 J. T. Carneiro, T. J. Savenije, J. A. Moulijn and G. Mul, J. Phys. Chem. C, 2010, 114, 327-332.

255 S. Bakardjieva, J. Subrt, V. Stengl, M. J. Dianez and M. J. Sayagues, Appl. Catal., B, 2005, 58, 193-202.
256 G. Riegel and J. R. Bolton, J. Phys. Chem., 1995, 99, 42154224.

257 J.-G. Li, T. Ishigaki and X. Sun, J. Phys. Chem. C, 2007, 111, 4969-4976.

258 V. Luca, J. Phys. Chem. C, 2009, 113, 6367-6380.

259 A. R. Armstrong, G. Armstrong, J. Canales and P. G. Bruce, Angew. Chem., Int. Ed., 2004, 43, 2286-2288.

260 R. I. Bickley, T. Gonzalez-Carreno, J. S. Lees, L. Palmisano and R. J. D. Tilley, J. Solid State Chem., 1991, 92, 178190.

261 T. Ohno, K. Sarukawa, K. Tokieda and M. Matsumura, J. Catal., 2001, 203, 82-86.

262 A. Kubacka, M. Fernandez-Garcia and G. Colon, Chem. Rev., 2012, 112, 1555-1614.

263 C.-H. Lin, J.-H. Chao, C.-H. Liu, J.-C. Chang and F.-C. Wang, Langmuir, 2008, 24, 9907-9915.

264 H.-L. Kuo, C.-Y. Kuo, C.-H. Liu, J.-H. Chao and C.-H. Lin, Catal. Lett., 2007, 113, 7-12.

265 J. Zhang, Q. Xu, Z. Feng, M. Li and C. Li, Angew. Chem., Int. Ed., 2008, 47, 1766-1769.

266 P. Romero-Gomez, A. Borras, A. Barranco, J. P. Espinos and A. R. Gonzalez-Elipe, ChemPhysChem, 2011, 12, 191-196.

267 T. Kawahara, Y. Konishi, H. Tada, N. Tohge, J. Nishii and S. Ito, Angew. Chem., 2002, 114, 2935-2937.

268 T. Ozawa, M. Iwasaki, H. Tada, T. Akita, K. Tanaka and S. Ito, J. Colloid Interface Sci., 2005, 281, 510-513.

269 S. Ardizzone, C. L. Bianchi, G. Cappelletti, S. Gialanella, C. Pirola and V. Ragaini, J. Phys. Chem. C, 2007, 111, 13222-13231.

270 T. A. Kandiel, A. Feldhoff, L. Robben, R. Dillert and D. W. Bahnemann, Chem. Mater., 2010, 22, 2050-2060.

271 H. Xu and L. Zhang, J. Phys. Chem. C, 2009, 113, 17851790.

272 A. Di Paola, G. Cufalo, M. Addamo, M. Bellardita, R. Campostrini, M. Ischia, R. Ceccato and L. Palmisano, Colloids Surf., A, 2008, 317, 366-376.

273 R. Roy, V. G. Hill and E. F. Osborn, J. Am. Chem. Soc., 1952, 74, 719-722.

274 Y. Hou, X. Wang, L. Wu, Z. Ding and X. Fu, Environ. Sci. Technol., 2006, 40, 5799-5803.

275 T. Yanagida, Y. Sakata and H. Imamura, Chem. Lett., 2004, 33, 726-727.

276 H. Yang, R. Shi, J. Yu, R. Liu, R. Zhang, H. Zhao, L. Zhang and H. Zheng, J. Phys. Chem. C, 2009, 113, 21548-21554.

277 L. Yuliati, T. Hattori, H. Itoh and H. Yoshida, J. Catal., 2008, 257, 396-402.

278 L. Yuliati, H. Itoh and H. Yoshida, Chem. Phys. Lett., 2008, 452, 178-182.

279 H. Tsuneoka, K. Teramura, T. Shishido and T. Tanaka, J. Phys. Chem. C, 2010, 114, 8892-8898.

280 Y. Hou, L. Wu, X. Wang, Z. Ding, Z. Li and X. Fu, J. Catal., 2007, 250, 12-18.

281 M. Muruganandham, R. Amutha, M. S. M. A. Wahed, B. Ahmmad, Y. Kuroda, R. P. S. Suri, J. J. Wu and M. E. T. Sillanpaa, J. Phys. Chem. C, 2011, 116, 44-53.

282 L.-C. Tien, W.-T. Chen and C.-H. Ho, J. Am. Ceram. Soc., 2011, 94, 3117-3122. 